\title{
Una década de investigación en la Facultad de Ciencia y Tecnología de la Universidad Pedagógica Nacional
}

\author{
A continuación los disitintos Departamentos Académicos \\ de la Facultad, presentan una revisión de los desarrollos \\ investigativos que se han realizado a lo largo de estos diez \\ años ininterrumpidos que cumple Tecné, Episteme y Didaxis.
}

\section{Desarrollo de los procesos investigativos en el Departamento de Biología de la Universidad Pedagógica Nacional. Aportes a la producción de conocimiento, la formación docente y la proyección social}

\author{
Édgar Orlay Valbuena U. \\ Carlos Arturo Sierra D. \\ Alice Marcela Gutiérrez P.*
}

Presentamos las tendencias de la investigación en el Departamento de Biología (DBI) de la Universidad Pedagógica Nacional (UPN), en lo que atañe al objeto de estudio y las implicaciones tanto en la producción de conocimiento, como en los aportes a la formación docente y la proyección social. Hacemos énfasis en el periodo de los últimos diez años y esbozamos algunas características de las líneas de investigación consolidadas en este periodo de tiempo. Todo ello, sin descuidar los antecedentes que consideramos constituyeron el caldo de cultivo para alcanzar los logros actuales. La dinámica de investigación en el DBI ha cambiando, así: en un comienzo estaba soportada principalmente en los trabajos de grado de los futuros profe-

* Profesores del Departamento de Biología. Universidad Pedagógica Nacional. sores, y en la actualidad se desarrolla al interior de grupos y líneas de investigación lideradas por los formadores de formadores. En cuanto a los objetos de investigación, éstos son diversos y han tenido un giro, pasando de tendencias en la disciplina biológica a problemas relativos a la Educación, la Pedagogía y la Didáctica de la Biología.

Las investigaciones del DBI han aportado elementos fundamentales en la formación de docentes, al constituir la base para la formulación de Proyectos Curriculares de pregrado (Licenciatura en Biología) y de posgrado (Especialización en Enseñanza de la Biología). A su vez, dichos Proyectos Curriculares, especialmente el de pregrado, se desarrolla desde la perspectiva de la investigación formativa y constituye un sustrato para el fortalecimiento y/o la constitución de líneas de investigación. Pese a que los

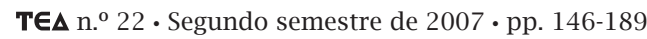


diferentes grupos de investigación del DBI han desarrollado trabajo con comunidades educativas y con profesores de ciencias y de Biología, en el contexto de cursos de actualización, programas de formación permanente de docentes y seminarios, en los ámbitos local, nacional e internacional, consideramos que podríamos aprovechar aún más los logros alcanzados desde de las diferentes investigaciones.

\section{Agentes dinamizadores de la investigación en el DBI. Un vistazo a las décadas de los 80 y 90}

La historia de las ciencias nos ha enseñado que el estado de ella, en un momento dado es el resultado de una convergencia de múltiples caminos, enfoques y condiciones. Esto también es válido para entender la actualidad del estado de investigación en el DBI. No hay una ruta continua y recta, sino ires y venires, desviaciones y reencuentros, cambios en el nivel de análisis, reformulaciones y readecuaciones metodológicas.

Lo anterior nos ha llevado a reconocer diferentes dinámicas que se han desarrollado en relación a la investigación y la formación de licenciados en Biología. Sin embargo, no queremos iniciar este recorrido sin hacer antes referencia a algunos aspectos que antecedieron y facilitaron espacios para la reflexión académica en torno a la misión y visión del DBI, durante los últimos diez años.

En la década de 1970, la formación de licenciados en Biología estuvo centrada en la 'Preparación metodológica para organizar y administrar contenidos', un acercamiento a la 'Ciencias de la educación’ (Psicología, Sociología y Filosofía de la Educación) y un marcado acento en los saberes de la Biología. La investigación era algo realizado por unos pocos y lejos del entorno inmediato.

Con la reforma del plan de estudios en la década de 1980, se incluyó como uno de los objetivos de formación 'Desarrollar aptitudes para la investigación', y en los fines que se '...puedan realizar investigación, docencia y aplicar sus conocimientos científicos en la solución de problemas nacionales' (DBI, 1984, p. 5). El Plan estaba basado en la estructura conceptual de la Biología, áreas de integración y niveles de complejidad y organización, lo que implicaba un trabajo de análisis de la Historia, la Epistemología, la Pedagogía y Didáctica y aplicabilidad de los conceptos que permitían dar cuenta de los hechos u objetos de conocimiento abordados. Este enfoque permitió vislumbrar una manera distinta de pensar las relaciones que emergen en el quehacer del docente, posibilitó entre otras cosas el desarrollo de trabajos que, aunque incipientes, mostraban una dimensión distinta al mero dictar clases y abría la puerta a la investigación educativa como parte integral de la actividad del docente. Se introdujo el trabajo de grado como requisito parcial para optar al título de licenciado.

La intencionalidad declarada en el documento marco del Plan de Estudios de 1984, era básicamente formar a los futuros maestros en la investigación pedagógica y didáctica. Sin embargo, los profesores formadores, en su mayoría, no estábamos preparados para esa tarea y nos refugiamos en la disciplina biológica para hacer los pinitos en investigación, orientando una enorme cantidad de trabajos de grado, que cubrían una amplia gama de temáticas, 
enfoques y problemáticas. Esto nos permitió instaurar una tradición que, con diferentes estilos de trabajo, nos condujo a formar grupos alrededor de temáticas u orientaciones metodológicas y epistemológicas.

Las continuas discusiones académicas, en el marco del Movimiento Pedagógico, nos movilizaron conceptualmente y redireccionamos los esfuerzos hacia la búsqueda de una identidad como Departamento, desde lo disciplinar y lo pedagógico en un sistema de ideas que se fue configurando como saber escolar. La particularidad de nuestra profesión empezó a ser entendida como un complejo multidimensional en el que el quehacer cotidiano involucraba los saberes de la disciplina a enseñar, la reflexión sobre las relaciones emergentes en la actividad docente, el análisis de la Lógica, la Historia y la Filosofía de la Ciencia como marco para la construcción de los conceptos y el desarrollo de las potencialidades de los estudiantes. Hubo un desplazamiento del centro de atención, ahora lo importante ya no era sólo el estudiante o el maestro sino la construcción del conocimiento por los actores involucrados en el proceso y por ello, fue importante estudiar las condiciones que afectaban esa construcción. Se hizo necesario, entoces, indagar sobre las preconcepciones, nociones o preconceptos que tenían, tanto alumnos como maestros, se buscó caracterizar las estrategias didácticas más efectivas, es decir, hubo un cambio de mirada.

Poco a poco, la investigación se fue constituyendo en un ejercicio de la actividad docente en el DBI. A mediados de la década del 90, era el centro, el eje de la formación de los futuros maes- tros y el DBI tenía ya varios grupos de investigación consolidados, con líneas y proyectos en desarrollo. Sin embargo, Puerto y Rodríguez (1995), hacen la caracterización de las tendencias de 110 proyectos de grado realizados entre 1989 y 1994 encontrando que sólo 13 de los trabajos analizados se podían ubicar fácilmente en una de las cuatro líneas existentes en ese entonces (Enseñanza de la Biología en Colombia, Faunística y biodiversidad, Estudios en Calidad de Vida, Biodiversidad y conservación de los sistemas acuáticos del Santuario de Flora y Fauna de Iguaque). Las temáticas abordadas, según las autoras, eran: Didáctica (75), Biología (23), Comunidad (7), Historia (3) y Filosofía (2).

Es interesante anotar que el énfasis en lo didáctico se mantuvo durante ese periodo (representaba alrededor del 20\% de los trabajos, excepto en 1992, cuando bajó a un 8\%; mientras que el interés por lo disciplinar fue creciendo paulatinamente desde un 4.3\% en 1989 hasta alcanzar el 43\% en 1994. Lo anterior nos llevó a tener que visualizar y proyectar el trabajo formativo y de investigación, pues la pregunta que planteábamos era: ¿estamos descuidando la formación pedagógica y sobrevalorando lo disciplinar de la Biología?

\section{Desarrollo de la investigación en el BDI. La última década, 1997-2007}

Teniendo en cuenta el contexto anterior, el DBI tenía un reto académico, pues la idea era formar licenciados en Biología que reconocieran su profesión más allá de la disciplina, dándole un espacio de análisis y construcción a la formación pedagógica y didáctica desde la investigación educativa. 
El comité de práctica, entre los años 1995 y 1998, realizó debates en torno a la formación de los licenciados en Biología y el papel que juegan allí las prácticas pedagógicas. Este proceso que se inició con la investigación Análisis de las Características del Maestro en Formación de la Licenciatura en Biología (Castaño et ál., 1998), en la que se consideraban como puntos críticos a considerar en la formación del docente en Biología el poco interés por la Pedagogía y la falta de identificación con la profesión docente. Consideraba que estos aspectos se hacen más críticos cuando se desconocen sistemáticamente las características y creencias de los estudiantes en relación con aspectos afectivos y culturales, tales como el sentido que le dan a sus vidas, su visión de país, la imagen que tienen de la profesión docente y de la Educación; las relaciones que encuentran entre la disciplina biológica y la formación pedagógica, entre otros aspectos 2 .

Es así como el nuevo proyecto curricular se viabiliza gracias a dos situaciones:una relacionada con el acontecer del Departamento y su experiencia en el desarrollo de la propuesta de formación de los licenciados en Biología; la otra con el planteamiento que se hace desde el Proyecto Político Pedagógico de la Universidad Pedagógica Nacional en el año de 1997, el cual aporta el cuerpo fundamental y marco conceptual para la reestructuración de las propuestas formativas al interior de cada Departamento. Estas situaciones, llevan al DBI

2 Declaración de la profesora Norma Constanza Castaño, Coordinadora del comité de práctica del Programa de Licenciatura en Biología de ese entonces. a buscar espacios para el encuentro académico que le permita replantearse la idea del licenciado en Biología que quiere formar, llegando así al año 2000.

Estas intenciones se objetivaron en la estructuración del actual Proyecto Curricular Licenciatura en Biología (PCLB), en el que la dimensión investigativa es el eje articulador: cada eje curricular o semestre se organiza con Núcleos Integradores de Problemas (NIP), para ser resueltos por los estudiantes con el concurso de los docentes de todas las asignaturas o componentes que hacen parte del semestre. Estamos convencidos de que la educación formal debe pretender una formación integral, abandonando la atomización de saberes y adoptando un enfoque sistémico, y por lo tanto interdisciplinario, que posibilite al estudiante la construcción de una visión integral y dinámica de la Naturaleza y la formación y desarrollo de un verdadero "espíritu científico"; lo que nos puso en otro nivel de análisis que implicaba el uso de la investigación pedagógica, didáctica y en la Biología como elementos formativos del maestro formador, desde los cuales se podría organizar el currículo con una perspectiva que respondiera a las demandas sociales, del Ministerio y de la Universidad, pero también a la lógica y estructura de la disciplina.

Esta situación se toma como un indicador de la necesidad de identificar otros enfoques y alternativas en la enseñanza de las diferentes disciplinas, de tal forma que los estudiantes logren un mayor nivel de aprendizaje significativo y comprensivo y así se puedan maximizar las posibilidades de éxito en un mundo cambiante y veloz. 
De esta forma, en el desarrollo del PCLB se suscitan preguntas que encontrarán nuevas posibilidades de respuestas en maestros preparados para el abordaje, la nueva perspectiva lleva a los grupos a viabilizar las problemáticas a través de proyectos de investigación que son posibles gracias a los Proyectos de Facultad, el Centro de Investigaciones de la Universidad Pedagógica, CIUP, el Instituto para la Investigación y el Desarrollo Pedagógico IDEP, Colciencias y el tiempo que se asigna en la carga horaria de los profesores ocasionales y catedráticos.

Las condiciones están dadas y las posibilidades de hacer investigación nos llevan a desarrollar investigaciones que dan posibilidades de consolidar grupos y/o líneas de investigación. A continuación, presentamos una breve descripción de las principales finalidades de las 11 líneas de investigación que actualmente hacen parte del DBI, de acuerdo con la información dada por cada uno de los grupos:

- Biotecnología y Educación: proyectar socialmente el análisis crítico y la reflexión de los adelantos de la biotecnología, diseñando estrategias que faciliten la enseñanza / aprendizaje de las ciencias, promoviendo la alfabetización científica que facilite la comprensión de las relaciones CTS.

- Desarrollo sostenible en el sector rural: sensibilizar a las comunidades Educativas del sector rural, hacia la conservación y protección del sistema ambiental local bajo los principios de la sostenibilidad. Haciendo especial énfasis en el escolar campesino, para que éste tome actitudes favorables, hacia la protección y conservación de la vida.
- Estudios ecológicos para la conservación de los sistemas acuáticos de la Región Andina: sus principales propósitos son: caracterizar los factores físico-químicos y biológicos de los sistemas acuáticos de esta región. Realizar estudios orientados a evaluar la calidad biológica de los sistemas acuáticos de esta región. Proponer procesos de cualificación de docentes de educación básica y media de los planteles educativos de esta región, en aspectos relacionados con el conocimiento de la biodiversidad, conservación y manejo sostenible de los recursos hídricos.

- La Educación Ambiental en el contexto educativo colombiano: construir conocimiento sobre Educación Ambiental en aspectos conceptuales, pedagógicos, metodológicos y didácticos a partir de los desarrollos teóricos y la identificación de los enfoques y tendencias en el campo en los diferentes contextos educativos, particularmente en la escuela.

- Estudios en calidad de vida y Probleduciencias: el principal objetivo del trabajo tanto en calidad de vida como en probleduciencias es la producción de conocimiento en cada campo. En calidad de vida se logra, mediante el diseño, ejecución, evaluación y propuesta de estrategias de contribución al mejoramiento de la calidad de vida y el desarrollo humano a través de la educación así como de contribución a la generación de políticas pertinentes a su objeto. Mientras que en Probleduciencias, la producción se centra en el campo de la Didáctica, con el fin de contribuir a la consolidación de una postura teórica unificada, pero flexible, en el ámbito de la enseñanza 
de las ciencias, la educación centrada en la resolución de problemas, a partir del modelo "Resolución de problemas en una perspectiva de investigación".

- Faunística y conservación de artrópodos: generar conocimiento, actividades educativas y aplicaciones pedagógicas en torno a la artropofauna contribuyendo con ello a su conservación y utilización, mejorando así la calidad de vida de los colombianos. Así mismo, adaptación, implementación y validación de propuestas pedagógicas, alrededor de la Ecología, conservación y educación ambiental, utilizando preferiblemente insectos.

- Conocimiento profesional del profesor de ciencias: reflexionar en torno a la construcción de este tipo de conocimiento, el cual caracteriza al docente de Ciencias Naturales y lo diferencia del quehacer de otros profesionales. En ese sentido, pretende producir conocimiento pedagógico y didáctico relacionado con las fuentes, los componentes y las relaciones que hacen posible la construcción de dicho conocimiento, el cual posee un estatus epistemológico diferenciado, que le permite al docente integrar y transformar los saberes que confluyen en la enseñanza de las Ciencias.

- Ciencias, acciones y creencias: trabajar acerca de las creencias de los profesores de ciencias sobre la naturaleza de la Ciencia, la enseñanza y el aprendizaje; y la identificación de algunas implicaciones de estas creencias en la enseñanza y en el aprendizaje. También, trabaja en la experimentación de modelos alternativos para mejorar la enseñanza de las ciencias que produzcan impactos positivos en el aprendizaje de los estudiantes sobre: los conceptos científicos, las prácticas de laboratorio, la resolución de problemas, el mejoramiento de las actitudes hacia el aprendizaje y el análisis crítico de las relaciones ciencia, tecnología y sociedad.

- Pensamiento del profesor: cuestionar, construir y transformar conocimientos educativos a partir de las reflexiones sobre la enseñanza de la Biología y las ciencias experimentales. Interpretando y caracterizando varias de las principales acciones y problemáticas que afrontan los profesores en la educación básica secundaria, desde fundamentos pedagógicos y didácticos actuales para contextos de realidades colombianas.

- Trayectos y aconteceres: estudios del ser y el quehacer del maestro desde la Pedagogía: aportar a la construcción de un saber propio de la Pedagogía desde la indagación histórica de las prácticas y los discursos sobre educación, enseñanza, aprendizaje, maestro, estudiante, escuela, saber pedagógico y disciplinas de enseñanza. Además, de establecer las condiciones de posibilidad de algunas prácticas y discursos relacionados con la Pedagogía.

- Desarrollo del pensamiento biológico y de la comunicación en el niño: caracterizar las formas de pensar de los niños acerca de lo vivo y construir un modelo que permita comprender el desarrollo cognitivo y propiciar 
aprendizajes en esta área de conocimiento. Busca también, comprender las interacciones que se suceden en el aula de clase de ciencias en lo que respecta a los diversos saberes construidos acerca de lo vivo y los diferentes tipos de discurso para la expresión de dichos saberes y las interacciones que enmarcan el trabajo en el aula de clase.

\section{¿Cuál ha sido el objeto de investigación en el Departamento de Biología?}

Las investigaciones realizadas durante los últimos diez años en el DBI, ya sea en el contexto de grupos o líneas de investigación se ocupan de diversos problemas. En la Tabla 1 se agrupan los estudios realizados, de acuerdo con los objetos y problemas de investigación; igualmente se presentan los títulos de algunos de los proyectos realizados (financiados por el Centro de Investigaciones de la Universidad Pedagógica Nacional, CIUP, la gran mayoría; Colciencias y el IDEP) y las referencias de algunas publicaciones gestadas a partir de los diferentes proyectos. Cabe señalar que debido a la limitación en el espacio disponible, el presente artículo referencia tan sólo una muestra de las producciones de los grupos de investigación del DBI.

A partir de la tabla, podemos reconocer que una cantidad significativa de investigaciones atañen al campo de investigación en Enseñanza-aprendizaje de las ciencias y de la Biología. Los estudios al respecto se refieren a cinco dimensiones:

- Los referentes históricos y epistemológicos de la Biología y de la enseñanza de esta ciencia en Colombia.
- La educabilidad y enseñabilidad de áreas referentes a temáticas contemporáneas en la Biología, como son la salud, la conservación de la biodiversidad, la Ecología y Biotecnología.

- La enseñabilidad de temáticas específicas, concretamente de conceptos de Botánica.

- Modelos y estrategias para la enseñanza de las ciencias y de la Biología, tales como la resolución de problemas y la utilización de las nuevas tecnologías de comunicación.

- Análisis de representaciones y de pensamiento acerca de aspectos biológicos, tal es el caso de las investigaciones sobre el pensamiento de los niños sobre lo vivo, y de las representaciones sociales acerca microorganismos.

La realización de dichos estudios corresponden principalmente a las líneas de investigación: Pensamiento del profesor, Estudios en calidad de vida, Estudios ecológicos para la conservación de los sistemas acuáticos, faunística y conservación de artrópodos, y Biotecnología y Educación. Es de resaltar que los resultados de estas investigaciones, además de contribuir en la producción de conocimiento pedagógico y didáctico, han aportado importantes elementos para la estructuración de Proyectos Curriculares tanto de pregrado (Licenciatura en Biología) como de postgrado (Especialización en Enseñanza de la Biología), y se han constituido en el pilar para la realización de eventos educativos de orden local, nacional (encuentros de Enseñanza de la Biología y la Educación Ambiental, diplomados dirigidos a maestros del Distrito y la Secretaría de Salud, así como encuentros de experiencias en 
Biotecnología en los niveles de educación básica y media) e internacionales (cursos Internacionales de Educación para la Conservación en el geotrópico UPN-OEA-ICETEX).

Uno de los campos en los que más se ha investigado en el DBI es el de las creencias, pensamiento y conocimiento profesional del profesor de ciencias y de Biología. Al respecto la producción ha sido nutrida en lo que tiene que ver con la caracterización de las concepciones y del pensamiento de docentes en ejercicio, y derivado de ello las implicaciones en la formación permanente de docente, y la formulación y desarrollo de propuestas para el mejoramiento de las prácticas pedagógicas. En los dos últimos años venimos desarrollando investigaciones con futuros profesores de Biología, dichos estudios están orientados a caracterizar sus concepciones acerca de diferentes componentes del conocimiento profesional del profesor de Biología; además estamos identificando los elementos formativos al interior del Proyecto Curricular de Licenciatura en Biología que contribuyen a la construcción y reconstrucción de dicho conocimiento profesional.

La caracterización de la formación docente en el DBI, se reconoce desde dos puntos de vista: uno relacionado con el aporte que desde la investigación se hace a la cualificación de docentes en ejercicio, encontrado que este campo es propicio y oportuno para la proyección social desde la investigación que hacen algunas líneas, como por ejemplo: la serie de conversatorios de Trayectos y Aconteceres, los cuales se han ido desarrollando desde hace varios años, talleres que desde Ciencia, acciones y creencias y Pensamiento del profesor se han llevado a cabo con docentes en formación y del Distrito Capital, entre otros.

El otro aspecto está relacionado con la flexibilidad que tiene el PCLB en cuanto a la posibilidad que se tiene para abordar diferentes retos y problemáticas, los cuales se van reconociendo en el desarrollo del mismo. Desde esta perspectiva, se han concebido y desarrollado varias investigaciones que responden a la formación docente, con una mirada de reconocimiento y autoevaluación tanto de la propuesta curricular, como lo son los "proyectos de evaluación del proyecto curricular fases I y II"; así como de los estudiantes, desde proyectos como: Las condiciones de autonomía de los estudiantes del Proyecto Curricular Licenciatura en Biología y Análisis de las características del maestro en formación de la Licenciatura en Biología, entre otros. Los resultados de estas investigaciones han permitido recocernos y plantear proyecciones al interior del Departamento en aras de mejorar la calidad en la formación de los futuros maestros.

El campo de investigación relacionado con la Pedagogía, hace énfasis en la reflexión y el sentido que se le da a esta ciencia como saber propio de los maestros, es otra de las características que desde diferentes líneas e investigaciones se le ha dado a esta área de saber. Investigaciones como las realizadas, en su momento desde Violencia y escuela, en donde se establecieron los imaginarios de violencia presentes en la relación maestro-estudiante, que dieron paso al planteamiento de otros trabajos relacionados con la práctica pedagógica 
en la generación, trasformación y y/o disminución de la violencia en la escuela. Los aportes desde este campo le han permitido al Departamento rescatar al maestro como profesional, estudiándolo desde su ser y su quehacer en el ámbito pedagógico.

Cabe destacar que los diferentes grupos de investigación, además de haber publicado artículos y libros, han socializado los resultados de los estudios en numerosos eventos nacionales e internacionales, entre los que destacamos: congresos de la Asociación Colombiana de Ciencias Biológicas, congresos internacionales de enseñanza de la Biología organizados por la Asociación de Docentes de Ciencias Biológicas de Argentina, congresos internacionales de profesores de ciencias organizados por la revista TE $\Delta$, congresos internacionales de enseñanza de las ciencias organizados por la revista Enseñanza de las Ciencias, congresos nacionales de la Sociedad Colombiana de Entomología, SOCOLEN, congresos internacionales de microbiología ambiental y microbiología industrial organizados por la Pontificia Universidad Javeriana de Bogotá, entre otros.

Otro aspecto que no queremos dejar pasar desapercibido es el aporte de la investigación del DBI en los procesos de formación inicial de docentes. Así, el enfoque complejo y la estructura del Proyecto Curricular de Licenciatura en Biología (PCLB) obedece a las contribuciones de las líneas de investigación, lo que conlleva a concebir dicho proyecto como una investigación de autoevaluación formativa. Los énfasis del ciclo de profundización del PCLB son formulados y desarrollados fundamentalmente con base en cuatro líneas de investigación. De otra parte, los problemas que abordan los futuros licenciados en Biología en su práctica pedagógica integral (en el ciclo de fundamentación del PCLB) son orientados por los diferentes grupos de investigación. De igual manera, los proyectos pedagógicos desarrollados por los docentes en formación, en el marco de la práctica docente en el ciclo de profundización, son realizados al interior de proyectos de investigación de las once líneas. Es de resaltar que todos los trabajos de grado son realizados por los estudiantes del PCLB al interior de los grupos de investigación, y generalmente contribuyen al cumplimiento de objetivos de investigaciones puntuales. Una tendencia en los últimos años es que los trabajos de grado correspondan a la continuación de los proyectos pedagógicos desarrollados en la práctica docente.

\section{Conclusiones}

El reconocimiento del contexto en que aconteció la investigación que hoy en día se desarrolla en el DBI permite dar razón de las trasformaciones significativas en cuanto a la investigación, la producción de conocimiento y la formación de los licenciados en Biología.

La investigación en el DBI ha permitido construir conocimiento en las áreas disciplinar, pedagógica y didáctica.

A través de la investigación se ha fortalecido la propuesta de formación de licenciados en Biología tanto en pregrado como en postgrado.

El reto que enfrentamos hoy en día como comunidad académica es avanzar en la proyección social, teniendo en cuenta los logros alcanzados en nuestras investigaciones. 
Tabla 1. Agrupación de las investigaciones del Departamento de Biología de acuerdo con los campos y objetos de estudio

\begin{tabular}{llll}
\hline CAMPOS DE & OBJETOS DE & ALGUNAS INVESTIGACIONES & ALGUNAS \\
INVESTIGACIÓN & INVESTIGACIÓN & REALIZADAS & PUBLICACIONES \\
\hline
\end{tabular}

Historia y epistemología de la Biología.

Historia de la enseñanza de la Biología en Colombia.

Los estudios de calidad de vida:

Alternativa de educación basada en

Educación para la salud - Estudios en calidad de vida.

la investigación.

Mejoramiento de la calidad de vida en relación con ruido en comunidades de diferentes niveles educativos.

Incorporación de nuevas colombiana. tecnologías de la información en el currículo del Departamento de Biología, Área Ecología.

Investigación en faunística y conservación, con énfasis en los artrópodos.

conservación de la biodiversidad. currículo del Instituto Pedagógico Nacional.

Biotecnología y Educación.

Incidencia de los proyectos escolares en biotecnología en la enseñanza de de las ciencias en Bogotá.

aprendizaje de las Ciencias y de la Biología
Educación en ecología

Incorporación de la Biotecnología al

Chona, G.; Castaño, N.; Arteta, J; (1998) Lo que nos dice la historia de la enseñanza de la Biología en Colombia.

Jessup, M. (1999). Evaluación de

Metodologías de Investigación-

Interacción para el Desarrollo

Educativo.

Jessup, M., Pulido, R. (1998)

Los estudios de calidad de vida. Alternativa en Educación basada en la investigación.

Rincón, M. et ál. (2004) Trichoptera del Santuario de Iguaque (Boyacá, Colombia) y su relación con la calidad del agua.

Torres, R. y García, M. (1998)

Los estudios faunísticos y de

bioproyección en la educación de los colombianos.

Valbuena, E. (1998). Contribución al

desarrollo de biotecnología desde la educación en los niveles de básica y media.

Pulido, et ál. (2006). Investigaciones escolares en biotecnología. Una estrategia que involucra situaciones problemáticas.

Álvarez, E. (1998). El aprendizaje de algunos conceptos fundamentales en el campo de la Botánica. Una experiencia de investigación en el aula.

Álvarez, E. (2001). Aplicación de una estrategia metodológica para el aprendizaje del concepto fruto.

Enseñanza de contenidos Enseñanza de conceptos sobre biológicos específicos.

Botánica.

\begin{tabular}{lll}
\hline & $\begin{array}{l}\text { El pensamiento espontáneo de los } \\
\text { niños acerca de la vivo. } \\
\text { Procesos de construcción de } \\
\text { sentido en la comunicación } \\
\text { profesor -estudiantes en el } \\
\text { aprendizaje de lo vivo en el ciclo de lo vivo. } \\
\text { educación básica primaria. }\end{array}$ & $\begin{array}{l}\text { Mireya, L., Castaño, N. (1988) Las } \\
\text { nociones de los niños acerca de lo } \\
\text { vivo. Implicaciones didácticas. }\end{array}$ \\
\hline $\begin{array}{l}\text { Representaciones sociales } \\
\text { en la enseñanza de las } \\
\text { ciencias y de la Biología. }\end{array}$ & $\begin{array}{l}\text { Las representaciones sociales de los } \\
\text { adolescentes asociadas a factores } \\
\text { de salud en el ambiente escolar. }\end{array}$ & $\begin{array}{l}\text { Fernández, M., Hernandez, A. } \\
\text { (2005) Las representaciones sociales } \\
\text { una forma de investigar la realidad } \\
\text { educativa. }\end{array}$ \\
\hline $\begin{array}{l}\text { Las TICs en la enseñanza } \\
\text { de las ciencias. }\end{array}$ & $\begin{array}{l}\text { Creencias acerca del uso de la } \\
\text { virtualidad en educación, para el } \\
\text { fortalecimiento de la formación de } \\
\text { docentes en ciencias. }\end{array}$ & $\begin{array}{l}\text { Molina, A. et ál., (2007) La } \\
\text { educación en ciencias mediada por } \\
\text { la virtualidad. Una mirada desde el } \\
\text { saber de los maestros. }\end{array}$ \\
\hline $\begin{array}{l}\text { La resolución de } \\
\text { problemas en la } \\
\text { enseñanza de las ciencias. }\end{array}$ & & $\begin{array}{l}\text { Jessup, M. (1998) Resolución de } \\
\text { Problemas y Enseñanza de las }\end{array}$ \\
& & $\begin{array}{l}\text { Ciencias Naturales. Revista de la } \\
\text { Facultad de Ciencia y Tecnología TEA: } \\
\text { (3) 41-52. }\end{array}$ \\
\hline
\end{tabular}


Tecné, Episteme y Didaxis n. ${ }^{\circ} 22,2007$

\begin{tabular}{|c|c|c|c|}
\hline \multirow{3}{*}{ Estudios biológicos } & Ecología & $\begin{array}{l}\text { Trichoptera del Departamento de } \\
\text { Cundinamarca y su relación con la } \\
\text { calidad del agua. }\end{array}$ & Ruiz y Rincón (2002) \\
\hline & Biotecnología & $\begin{array}{l}\text { Implementación del cepario } \\
\text { bacteriano del DBI. }\end{array}$ & $\begin{array}{l}\text { Puentes, M. et ál. (1999). Aislamiento } \\
\text { y caracterización de cepas de } \\
\text { Bacillus thuringiensis a partir de } \\
\text { suelo del municipio de Mundo Nuevo } \\
\text { (Cundinamarca). }\end{array}$ \\
\hline & Biodiversidad & $\begin{array}{l}\text { Investigación en faunística y } \\
\text { conservación con énfasis en los } \\
\text { artrópodos. }\end{array}$ & $\begin{array}{l}\text { Torres, R. y Le Croom, (1997). Una } \\
\text { nueva especie de Pedaliodes Butler, } \\
1867 \text { de la Cordillera oriental de } \\
\text { Colombia. Shilap }\end{array}$ \\
\hline \multirow[b]{2}{*}{$\begin{array}{l}\text { Educación } \\
\text { ambiental }\end{array}$} & $\begin{array}{l}\text { La educación ambiental } \\
\text { en el contexto escolar. }\end{array}$ & $\begin{array}{l}\text { Propuesta didáctica en educación } \\
\text { ambiental desde una perspectiva } \\
\text { interdisciplinar para incorporar la } \\
\text { dimensión ambiental a la escuela. }\end{array}$ & $\begin{array}{l}\text { Pérez, P., Porras, Y. (2007) } \\
\text { Identificación de las representaciones } \\
\text { de ambiente y educación ambiental } \\
\text { que circulan en la escuela. }\end{array}$ \\
\hline & $\begin{array}{l}\text { La educación ambiental } \\
\text { en el contexto rural. }\end{array}$ & $\begin{array}{l}\text { Aprendizajes significativos en } \\
\text { ciencias naturales, educación } \\
\text { ambiental y educación para la } \\
\text { salud desde la perspectiva de aulas } \\
\text { alternativas en escuelas rurales. }\end{array}$ & $\begin{array}{l}\text { Herrera, D. (1998) La granja integral } \\
\text { autosuficiente: estrategia educativa } \\
\text { de desarrollo sostenible en el sector } \\
\text { rural. }\end{array}$ \\
\hline \multirow{3}{*}{$\begin{array}{l}\text { Pensamiento y } \\
\text { Conocimiento } \\
\text { Profesional del } \\
\text { profesor de } \\
\text { Ciencias. }\end{array}$} & $\begin{array}{l}\text { Creencias de profesores de } \\
\text { Ciencias y de Biología. }\end{array}$ & $\begin{array}{l}\text { Concepciones de ciencia, } \\
\text { enseñanza y aprendizaje en } \\
\text { maestros de ciencia: Incidencia en } \\
\text { la educación científica en Santa Fe } \\
\text { de Bogotá. }\end{array}$ & $\begin{array}{l}\text { Reyes L., Salcedo, L. E. y Perafán, } \\
\text { G. A. (2001). Creencias acerca del } \\
\text { cambio en la enseñanza de las } \\
\text { ciencias. }\end{array}$ \\
\hline & $\begin{array}{l}\text { Pensamiento del profesor } \\
\text { de ciencias. }\end{array}$ & $\begin{array}{l}\text { Análisis del sistema de creencias } \\
\text { que orientan la práctica del profesor } \\
\text { de Biología. }\end{array}$ & $\begin{array}{l}\text { Chona, G.; et ál. (2001). Formas } \\
\text { de apropiación del discurso sobre } \\
\text { competencias por parte de los } \\
\text { profesores de ciencias naturales. }\end{array}$ \\
\hline & $\begin{array}{l}\text { Conocimiento Profesional } \\
\text { del profesor de Biología. }\end{array}$ & $\begin{array}{l}\text { Análisis de las concepciones } \\
\text { de los docentes en formación } \\
\text { inicial acerca del Conocimiento } \\
\text { Profesional del profesor de Biología. }\end{array}$ & $\begin{array}{l}\text { Valbuena, Castro y Sierra (2007). } \\
\text { El Conocimiento Biológico desde } \\
\text { la perspectiva del conocimiento } \\
\text { profesional del profesor de Biología. }\end{array}$ \\
\hline \multirow{3}{*}{$\begin{array}{l}\text { Formación } \\
\text { docente }\end{array}$} & $\begin{array}{l}\text { Características de futuros } \\
\text { profesores de Biología } \\
\text { e implicaciones en la } \\
\text { formación docente. }\end{array}$ & $\begin{array}{l}\text { Condiciones de autonomía de los } \\
\text { estudiantes del Proyecto Curricular } \\
\text { de Licenciatura en Biología. }\end{array}$ & $\begin{array}{l}\text { Pérez, R. et ál. (2003). Las condiciones } \\
\text { de autonomía en los estudiantes del } \\
\text { Proyecto Curricular de Licenciatura } \\
\text { en Biología. }\end{array}$ \\
\hline & $\begin{array}{l}\text { Autoevaluación curricular } \\
\text { en formación inicial. }\end{array}$ & $\begin{array}{l}\text { Investigación evaluativa del } \\
\text { Proyecto Curricular de Licenciatura } \\
\text { en Biología. }\end{array}$ & \\
\hline & $\begin{array}{l}\text { Competencias científicas } \\
\text { en docentes en ejercicio. }\end{array}$ & $\begin{array}{l}\text { Desarrollo de competencias } \\
\text { científicas y formación en valores. } \\
\text { Un estudio desde el pensamiento } \\
\text { del profesor de ciencias } \\
\text { experimentales. }\end{array}$ & $\begin{array}{l}\text { Arteta, J. et ál. (2005). La clase de } \\
\text { ciencias y la formación en valores. }\end{array}$ \\
\hline \multirow[t]{2}{*}{ Pedagogía } & Violencia y Escuela. & $\begin{array}{l}\text { Violencia y escuela: efectos de } \\
\text { la práctica pedagógica en el } \\
\text { mantenimiento, trasformación y/o } \\
\text { la generación de manifestaciones } \\
\text { o imaginarios de la violencia en las } \\
\text { instituciones escolares. }\end{array}$ & $\begin{array}{l}\text { Pinzón, et ál. (2004). Axolotl. } \\
\text { Trayectos y aconteceres, un proyecto } \\
\text { sobre violencia y escuela. }\end{array}$ \\
\hline & $\begin{array}{l}\text { El ser y el quehacer del } \\
\text { maestro. }\end{array}$ & $\begin{array}{l}\text { Enseñanza de la Biología y la } \\
\text { Pedagogía en el DBI de la UPN. }\end{array}$ & $\begin{array}{l}\text { Riveros (2006) Cómo se deja de ser } \\
\text { proyecto: Reflexión acerca de los } \\
\text { trayectos de la investigación. }\end{array}$ \\
\hline
\end{tabular}




\section{Referencias}

Arteta, J., Chona, G., Arteta, J., Fonseca, G., Ibáñez, X. \& Martínez, S. (2005) La clase de ciencias y la formación en valores. Estudio de caso de cómo los profesores propician valores desde sus acciones, revista Enseñanza de las ciencias. Número extra.

Castaño, N., Chona, G., Pinzón, J., Lara, L., Valbuena, E., Martínez, S., Leudo, M., Arteta, J., Moncayo, G. y Herrera, D. (1998). Mirándonos para buscar sentido. TEA. Revista Facultad de Ciencia y Tecnología: Universidad Pedagógica Nacional (4), 11-26.

Chona, G., Castaño, N. \& Arteta, J. (1998). Lo que nos dice la historia de la enseñanza de la Biología en Colombia. Una aproximación. TES Revista de la Facultad de Ciencia y Tecnología: Universidad Pedagógica Nacional (4) 5-10.

Chona, G., Arteta, J., Fonseca, G. \& Martínez, S. (2001). Formas de apropiación del discurso sobre competencias por parte de los profesores de ciencias naturales. TE $\Delta$. Revista Facultad de Ciencia y Tecnología: Universidad Pedagógica Nacional (9), 80-94.

Fernández, M. \& Hernández, A. (2005). Las representaciones sociales una forma de investigar la realidad educativa. Revista Pedagogía y Saberes. Bogotá: Universidad Pedagógica Nacional (23) 19-28.

Herrera, D. (1998). La granja integral autosuficiente: estrategia educativa de desarrollo sostenible en el sector rural. TEA. Revista Facultad de Ciencia y Tecnología: Universidad Pedagógica Nacional (4) Edición digital.

Jessup, M. (1999). Evaluación de Metodologías de Investigación - Interacción para el Desarrollo Educativo. En: II
Foro preparatorio al simposio nacional sobre investigación educativa. Relaciones y Tensiones entre Innovación e Investigación Educativa, Enseñanza de las Ciencias y Tecnología, Bogotá. (1) $77-92$.

Jessup, M. y Pulido, R. (1998). Los estudios de calidad de vida. Alternativa en Educación basada en la investigación. TEA. Revista de la Facultad de Ciencia y Tecnología: Universidad Pedagógica Nacional (4) 111-124.

Jessup, M. (1998). Resolución de Problemas y Enseñanza de las Ciencias Naturales. TEA. Revista de la Facultad de Ciencia y Tecnología: Universidad Pedagógica Nacional 8(3) 41-52.

Martínez, S., Bernal, A., Gómez, A., Ortiz, E., Zafra, S., Ibáñez, S., Pedraza, M., Oicatá, M., Fonseca, G. \& Arteta, J. (2003). De la pregunta al proyecto. En: Emociones y Razones para innovar en la Enseñanza de las Ciencias. Siete experiencias pedagógicas de la Escuela Básica. Alcaldía Mayor de Bogotá. Instituto para la Investigación Educativa y Desarrollo Pedagógico, IDEP.

Pinzón, J., Rodríguez, L., Riveros, O. y Roa, P. (2004). Axolotl. Trayectos y aconteceres, un proyecto sobre violencia y escuela. Bogotá: Universidad Pedagógica Nacional.

Reyes L., Salcedo, L. E. y Perafán, G. A (2001). Creencias acerca del cambio en la enseñanza de las ciencias. En: Enseñanza de las ciencias, número extra, VI congreso Tomo I.: 369.

Rincón, M. Medellín, F. \& Ramírez, M. (2004) Trichoptera del Santuario de Iguaque (Boyacá Colombia) y su relación con la calidad del agua. Revista Colombiana de Entomología: Guadalupe Ltda. (30)2,197-203 
Riveros, O. (2006). Cómo se deja de ser proyecto: reflexión acerca de los trayectos de la investigación. En: Los bordes de la pedagogía. Universidad Pedagógica Nacional - Instituto Nacional de Pedagogía. 35-61

Ruiz, V. \& Rincón, M. (2002). Calidad ecológica del agua del río Villeta. TES. Revista Facultad de Ciencia y Tecnología. No 12.

Torres, R. y García, M. (1998). Los estudios faunísticos y de bioproyección en la educación de los colombianos. TE $\Delta$. Revista Facultad de Ciencia y Tecnología. No (14) Edición digitalizada.

Torres, R. y Le Crom, J.F. (1997). Una nueva especie de Pedaliodes Butler, 1867 de la Cordillera oriental de Colombia. Shilap Revista de Lepidopterología, 25 (100): 213-218.

Mireya, L. y Castaño, N. (1988). Las nociones de los niños acerca de lo vivo. Implicaciones didácticas. TE $\Delta$. Revista de la Facultad de Ciencia y Tecnología. (4) 49-57.

Molina, A., Ortiz, G. y Waltero, C. (2007). La educación en ciencias mediada por la virtualidad. Una mirada desde el saber de los maestros. En: Investigación e innovación en la enseñanza de las ciencias. Bogotá: Universidad Católica de Colombia. Edición digital.

Pérez, P. y Porras, Y. (2007). Identificación de las representaciones de ambiente y educación ambiental que circulan en la escuela. TEA. Revista de la Facultad de Ciencia y Tecnología: (21) Edición digitalizada.

Pérez, R., Mireya, L., Martínez, S., Velasco, A., Martínez, S. y Pedraza, M. (2003). Las condiciones de autonomía en los estudiantes del Proyecto Curricular de
Licenciatura en Biología. TE $\Delta$. Revista Facultad de Ciencia y Tecnología. Bogotá: V. Extra, 124-126.

Programa de Licenciatura en Biología. Nuevo plan de estudios. Junio 1984. Departamento de Biología Universidad Pedagógica Nacional. Documento de circulación interna.

Puentes, M., Mozo, N. y Valbuena, E. (1999). Aislamiento y caracterización de cepas de Bacillus thuringiensis a partir de suelo del municipio de Mundo Nuevo (Cundinamarca). Revista de la Asociación Colombiana de Ciencias Biológicas ACCB, $11 \mathrm{~N}^{0} 1$, pp. 94-102.

Puerto, L. y Rodríguez, L. (1995). Resumen de los trabajos de grado y tendencias investigativas (1989-1994), Departamento de Biología, Universidad Pedagógica Nacional. Trabajo de grado

Pulido, M., Acosta, R., García, Y., Bolaño, P., Valbuena, E., López, S. y Chavarro, C. (2006). Investigaciones escolares en biotecnología una estrategia que involucra situaciones problemáticas. En: Ciencias, racionalidades y medio Ambiente. Bogotá: Editorial Pontificia Universidad Javeriana.

Valbuena, E. (1998). Contribución al desarrollo de biotecnología desde la educación en los niveles de básica y media. TES. Revista Facultad de Ciencia y Tecnología: (4) Edición digitalizada.

Valbuena, E., Castro A. y Sierra, C. (2007). El Conocimiento Biológico desde la perspectiva del Conocimiento Profesional del Profesor de Biología. Revista de la Asociación de Docentes de Ciencias Biológicas de Argentina (en prensa). 


\title{
2. La investigación en el departamento de física ${ }^{1}$
}

\author{
Rosa I. Pedreros M.* \\ Juan C. Orozco C.*
}

\section{Presentación}

La actividad investigativa del Departamento de Física se inició con la formulación y puesta en marcha del Programa de Maestría en Docencia de la Física en 1983, el cual fue concebido como una instancia para la investigación en la enseñanza de la Física, y en especial para la formación de una comunidad de investigadores en este campo que atendieran a la solución de los problemas relacionados con la enseñanza de la Física en los distintos niveles de la educación formal.

Se adoptó como estrategia central la generación de un clima cultural y de espacios que posibilitaran el intercambio de ideas y de trabajos, el análisis crítico de los mismos y la construcción de criterios de validez. Se buscó igualmente propiciar y promover la formación y consolidación de equipos de trabajo en torno a grandes aspectos problemáticos del campo de enseñanza de la física en nuestro país. Todo ello en la perspectiva de ir consolidando líneas de investiga-

1 En el texto se tiene en cuenta algunos los aspectos expuestos en los documentos de Lineamientos de los Programas de Maestría en Docencia de la Física, Especialización en Docencia de las Ciencias para los Niveles Básicos y Licenciatura en Física. Además, algunas de las ideas expuestas en las relatorías de las reuniones acerca de la investigación en el Departamento de Física de la Universidad Pedagógica Nacional.

* Profesores del Departamento de Física de la Universidad Pedagógica Nacional. ción en torno a las cuales se articulase el desarrollo de los trabajos de tesis con las propuestas de investigación de los equipos de profesores de la Maestría.

Los avances logrados en la investigación en el campo de la enseñanza de la física permiten destacar los siguientes supuestos y aspectos problemáticos como los ejes del programa de investigación que se ha venido consolidando en el Departamento y que orienta una buena parte de la actividad pedagógica en él:

- La Ciencia es una actividad que desarrolla una comunidad que se ha venido constituyendo históricamente como tal; en ese proceso la actividad científica adquiere sus rasgos característicos, en especial, se construyen los criterios (valores) comunes de trabajo. De aquí, que el problema de la producción científica y de la enseñanza de la Ciencia sea un problema eminentemente cultural.

- La enseñanza de las ciencias es ante todo una actividad cultural, y lo es en dos sentidos: la actividad del maestro es una práctica cultural y su acción se desarrolla fundamentalmente en el campo de la cultura. Se plantea como aspecto central la generación de condiciones que posibiliten la participación de nuestra cultura en la actividad de producción de conocimiento que sea considerado válido por nuestra sociedad. 
- La investigación educativa tiene un rasgo distintivo: ha de contribuir a la solución de problemas educacionales y a la transformación de las prácticas y de las condiciones estructurales en las que se lleva a cabo. Tal perspectiva implica partir del reconocimiento del carácter protagónico que tiene el maestro en la actividad educativa y cultural y que demanda la generación de condiciones para la consolidación de una comunidad académica de docentes y para la profesionalización de los mismos. De allí que la investigación educativa se conciba en lo esencial como investigación-acción, en la cual es condición necesaria la participación activa de los docentes en la dirección y gestión de la misma.

El Campo de Investigación, contempla la misión y visión del Departamento de Física, lo denominamos Enseñanza de las Ciencias en nuestro contexto, nos permite diferenciar y delimitar el área de acción y la idea de enseñanza nos lleva a comprender el carácter político de esta actividad y lo concerniente al contexto del aula. En la base del campo se tienen el desarrollo de las ciencias, la formación de docentes y el entorno del aula.

\section{La investigación en los programas curriculares del Departamento de Física}

Las actividades de los programas de posgrado del Departamento de Física han permitido poner en primer plano los aspectos culturales del quehacer científico y de la labor del maestro de ciencias. De otra parte, la dinámica alcanzada a través de la puesta en marcha del programa de Especialización en
Docencia de las Ciencias para el Nivel Básico mediante la conformación de nuevos grupos de investigación permitió emprender un programa de investigación en este sentido, que se expresa a través del proyecto de investigación Elementos para una enseñanza de las ciencias naturales desde una perspectiva cultural: recontextualizacion de saberes científicos.

En la investigación del Programa de Maestría en Docencia de la Física, se tiene en cuenta dos aspectos para la definición de las líneas de investigación: uno que hacía referencia a las concepciones sobre la naturaleza del conocimiento físico y a sus implicaciones para la enseñanza de la Física; el otro aludía a la forma como se asume el proceso de desarrollo del conocimiento individual y los procesos de aprendizaje en el aula de clases.

Alrededor del primer aspecto se han consolidado dos líneas de investigación: Conceptos y Teorías de la Física: Su desarrollo y enseñanza y Relación de la Física con otras disciplinas. Con relación al segundo aspecto se formula la línea de investigación: Praxis de la enseñanza de la Física.

En la Investigación del Programa de Especialización en Docencia de las Ciencias para el Nivel Básico, se tiene presente que los fenómenos educativos son esencialmente de carácter cultural y social. Las situaciones escolares son multifacéticas y complejas. En los procesos educativos confluyen innumerables factores y circunstancias que se correlacionan de muy variadas maneras; en ellos participan individuos con historias de vida diferentes, con diversos intereses, inquietudes y gustos, que al interactuar entretejen una red de relacio- 
nes y un entramado de significados que generan dinámicas únicas e irrepetibles (los sujetos no son homogéneos y uniformes, y por tanto los procesos educativos son vividos de diferentes maneras por cada uno de ellos) ${ }^{3}$.

La línea de investigación que soporta el programa se denomina, La enseñanza de las ciencias como actividad de construcción de explicaciones, organiza la actividad académica de la Especialización. En particular, la formulación y desarrollo de los espacios curriculares, los procesos de asesoría y acompañamiento a las prácticas innovadoras de los estudiantes y la dinámica investigativa de los equipos de docentes del programa. Además de los supuestos del programa de investigación del Grupo Física y Cultura, esta línea contempla los siguientes aspectos: La perspectiva fenomenológica en la construcción de explicaciones; la sistematización como práctica investigativa; los saberes científicos en situaciones de enseñanza le son inherentes procesos de traductibilidad y, la Ciencia no-diferenciada como una opción para la enseñanza de las ciencias en los niveles básicos.

En el Programa de Licenciatura en Física se contempla cuatro líneas de profundización: La enseñanza de las ciencias desde una perspectiva cultural; el experimento y las prácticas experimentales; la relación Física-Matemática y enfoques didácticos. La actividad global del Departamento tiene en cuenta los siguientes aspectos: el currículo y las prácticas educativas en el contexto de la Escuela; enseñanza y aprendizaje de

3 Discusiones y elaboraciones del Grupo de Física de Procesos del Departamento de Física de la Universidad Pedagógica Nacional (2000). las ciencias; construcción de material didáctico y uso de las TIC; las prácticas experimentales en la enseñanza de las ciencias y, la formalización y la relación Física-Matemáticas en la enseñanza de la Física.

\section{Grupos que soportan los programas de postgrado}

El Grupo Física y Cultura surge a mediados de 1989 y se ha venido consolidando en el marco de las actividades de los programas de Maestría en Docencia de la Física y de la Especialización en Docencia de las Ciencias para el Nivel Básico y de la Licenciatura en Física del Departamento de Física de la Universidad Pedagógica Nacional. Desde entonces ha emprendido actividades tendientes a desarrollar unas concepciones de ciencias y de profesionales de la enseñanza de las ciencias que involucren conceptos más adecuados para asumir las ciencias como una actividad que se da en el marco de un grupo social específico, con el ánimo de dar solución a sus propias necesidades, sean éstas de tipo económico, filosófico, estético.

El Grupo Física y Cultura ha realizado actividades en los campos de la investigación, la difusión y el desarrollo de una comunidad de Docentes en ejercicio. El trabajo de investigación se dirigió inicialmente a desarrollar las líneas "Conceptos y tteorías de la Física: su desarrollo y enseñanza" y "La relación de la Física con otras disciplinas”. Con posterioridad se trazaron lineamientos para el programa de investigación Elementos para una enseñanza de las ciencias naturales desde una perspectiva cultural: recontextualización de saberes 
científicos, planteado con los siguientes propósitos:

1. Contribuir a la formación de una cultura científica en la sociedad acorde con los procesos históricos y culturales de nuestro país, y a la formación de una comunidad académica de docentes en ciencias y con ello a la profesionalización de los maestros.

2. Contribuir a una apropiación crítica de las ciencias, en especial por parte de los docentes de ciencias, y construir elementos teóricos susceptibles de transformarse en criterios para la recontextualización de las prácticas y saberes científicos de modo que estos adquieran significado y sentido para los estudiantes.

El grupo se encuentra inscrito y reconocido por Colciencias desde el año 2002. Como resultado del proceso de clasificación, el grupo obtuvo la categoría B en 2004.

Tres aspectos estructuran el macro proyecto y orientan la acción investigativa de los docentes involucrados: 1) El análisis histórico-crítico de los saberes de las Ciencias, 2) Conformación de grupos y tradiciones de investigación; y, 3) Procesos de socialización de los logros de la investigación, conformación de comunidades académicas y transformación de prácticas de enseñanza de las ciencias, en torno al cual se articulan las diferentes actividades y proyectos que vinculan al grupo con los procesos de difusión de los resultados de la investigación, lo conectan con otros grupos de investigación en los contextos nacional e internacional y le posibilitan aportar a la conformación de una comunidad de investigadores en la enseñanza de la Física.

La producción del grupo en la última década ha sido en torno a: Construcción y desarrollo de un macro proyecto: elementos para una enseñanza de las ciencias naturales desde una perspectiva cultural: recontextualización de saberes científicos; desarrollo de cuatro proyectos de investigación dentro del macroproyecto desde el año de 1995; soporte del Programa de Maestría en Docencia de la Física; diseño y puesta en marcha del Programa de Especialización en Docencia de las Ciencias para el Nivel Básico; seis números de la revista Física y Cultura: Cuadernos de Historia y Enseñanza de la Física, con más de 30 artículos producidos en su mayoría por miembros del Grupo, que muestran el estado de desarrollo de las investigaciones; participación en la organización de eventos (i.e. Simposio sobre la Enseñanza de las Ciencias a nivel Básico y Medio); participación en eventos nacionales e internacionales con ponencias que presentan los resultados parciales o finales de las investigaciones realizadas en el marco de los programas de maestría y especialización y, elaboración de conceptos y categorías para el análisis histórico crítico de la actividad científica con fines pedagógicos y para la transformación de las prácticas de enseñanza de las ciencias.

Durante los últimos dos años se ha venido avanzando en la conformación de otros grupos de investigación. A la fecha, el Departamento de Física cuenta con un total de 6 grupos registrados en el sistema Gruplac de Colciencias, a saber: 


\begin{tabular}{|c|c|}
\hline Nombre del grupo & Proyectos \\
\hline $\begin{array}{l}\text { Física y Cultura } \\
\text { (Clasificado en categoría B) }\end{array}$ & $\begin{array}{l}\text { Enseñanza de la Física desde la perspectiva de los Sistemas Dinámicos. } \\
\text { La formalización y construcción de magnitudes físicas. } \\
\text { La enseñanza del electromagnetismo y la construcción de material } \\
\text { didáctico. } \\
\text { La actividad experimental en la enseñanza de las ciencias. } \\
\text { Las prácticas de sistematización en la formación de maestros. } \\
\text { Campos y partículas para la enseñanza de la Física. } \\
\text { Diseño de material didáctico multimedial. }\end{array}$ \\
\hline $\begin{array}{l}\text { Física y Matemática } \\
\text { (Clasificado en categoría C) }\end{array}$ & $\begin{array}{l}\text { Génesis y desarrollo de conceptos de la Mecánica Cuántica y la Relatividad. } \\
\text { Proceso de formalización matemática. } \\
\text { Enseñanza y aprendizaje de la Astronomía. } \\
\text { La relación Física-Matemática en la enseñanza de la Física. }\end{array}$ \\
\hline $\begin{array}{l}\text { El experimento en la enseñanza de las } \\
\text { ciencias }\end{array}$ & $\begin{array}{l}\text { El rescate de la experiencia sensible y los montajes experimentales de bajo costo. } \\
\text { Uso y construcción de interfases (uso del computador). } \\
\text { Elaboración de software educativo. }\end{array}$ \\
\hline Ecoperspectivas & $\begin{array}{l}\text { Problemas de Conocimiento (PC) una perspectiva compleja contemporánea para } \\
\text { la enseñanza de las ciencias en la Educación Básica y Media. } \\
\text { Los PC, una estrategia para la formación continuada de maestros de ciencias. } \\
\text { Los PC y las prácticas de enseñanza de las ciencias en el aula. }\end{array}$ \\
\hline Enfoques didácticos & Currículo, el aula y su entorno, la evaluación y la enseñanza de la Astronomía \\
\hline $\begin{array}{l}\text { enseñanza de la física como fenómeno } \\
\text { cultural }\end{array}$ & $\begin{array}{l}\text { Teorías de campo electromagnético, la matematización y la relación entre } \\
\text { la formalización matematización-experiencia. Además, el significado de la } \\
\text { enseñanza de la Física como fenómeno cultural. }\end{array}$ \\
\hline
\end{tabular}

\section{Investigaciones adelantadas en el Departamento de Física}

La investigación en el programa se ha venido desarrollando a través de proyectos que expresan los intereses y preocupaciones de los diferentes equipos de trabajo, los cuales han sido apoyados financieramente por la Universidad Pedagógica Nacional (Facultad de Ciencia y Tecnología o CIUP) y por instituciones como el IDEP y Colciencias. Además, han adelantado proyectos conjuntos con otras universidades como la Universidad de Antioquia y U. del Cauca; se ha elaborado un conjunto de tesis a nivel de maestría, trabajos de grado a nivel de Especialización y diversas monografías en la Licenciatura en Física.

\begin{tabular}{lll}
\hline AÑO & TíTULO DEL PROYECTO & AUTOR (ES) \\
\hline $1998-$ & $\begin{array}{l}\text { La Termodinámica Fenomenológica: Orígenes conceptuales y } \\
\text { elementos para una propuesta pedagógica. }\end{array}$ & $\begin{array}{l}\text { María Mercedes Ayala, Ángel Romero y Edwin } \\
\text { García. }\end{array}$ \\
\hline 1999 & $\begin{array}{l}\text { Historia y epistemología de las ciencias y la transformación } \\
\text { de las prácticas de enseñanza de las ciencias: análisis de los } \\
\text { procesos pedagógicos. }\end{array}$ & $\begin{array}{l}\text { Germán Bautista, Luz Dary Rodríguez, Ángel } \\
\text { Romero. }\end{array}$ \\
\hline $1998-$ & $\begin{array}{l}\text { El concepto organismo como articulador del conocimiento } \\
\text { biológico en la actualidad desde una perspectiva histórica. }\end{array}$ & $\begin{array}{l}\text { Steiner Valencia, José Vivente Bonilla, José } \\
\text { Pablo Garzón, Olga Méndez Núñez. }\end{array}$ \\
\hline 1999 & Análisis histórico-crítico sobre la hidrostática y la neumática. & Germán Bautista R. y Luz Dary Rodríguez. \\
\hline $1998-$ & Propuesta didáctica para la introducción a la física de procesos. & $\begin{array}{l}\text { Juan Carlos Orozco, José González, Clara Inés } \\
\text { Chaparro, Rosa Inés Pedreros y Jorge Vallejo. }\end{array}$ \\
\hline 1999 & $\begin{array}{l}\text { De la Mecánica a la necesidad de organizar los fenómenos } \\
\text { mecánicos: hacia la construcción de propuestas alternativas } \\
\text { para la enseñanza de la Mecánica. }\end{array}$ & $\begin{array}{l}\text { María Mercedes Ayala, Francisco Malagón, } \\
\text { Ángel Romero y Edwin García. }\end{array}$ \\
\hline \multirow{2}{19000}{} & $\begin{array}{l}\text { El concepto de organismo como organizador del conocimiento } \\
\text { actualidad desde una perspectiva histórica. (segunda fase). }\end{array}$ & $\begin{array}{l}\text { Steiner Valencia, José Pablo Garzón, Olga } \\
\text { Méndez Núnez, Gladis Jiménez Gómez y Juan } \\
\text { Carlos Forero Rojas. }\end{array}$ \\
\hline
\end{tabular}


Tecné, Episteme y Didaxis n. ${ }^{\circ} 22,2007$

\begin{tabular}{|c|c|c|}
\hline AÑO & TÍTULO DEL PROYECTO & AUTOR (ES) \\
\hline 2000 & Sistema piloto de tele-educación interactiva: Fase I. & $\begin{array}{l}\text { Germán Bautista, Olga Méndez, Margarita } \\
\text { Vargas, Juan Carlos Bustos, Martha Gómez, } \\
\text { Juan Carlos Forero, Olimpia Gary e Iván Flórez. }\end{array}$ \\
\hline 2001 & $\begin{array}{l}\text { Los problemas de conocimiento, una perspectiva compleja para } \\
\text { la enseñanza de las ciencias. }\end{array}$ & $\begin{array}{l}\text { Steiner Valencia Vargas, Olga Méndez Núñez, } \\
\text { José Pablo Garzón, Gladis Jiménez y Juan } \\
\text { Carlos Forero. }\end{array}$ \\
\hline 2001 & $\begin{array}{l}\text { De la mecánica a la actividad de organizar los fenómenos } \\
\text { mecánicos: hacia la construcción de propuestas alternativas } \\
\text { para la enseñanza de la Mecánica. }\end{array}$ & $\begin{array}{l}\text { María Mercedes Ayala, Francisco Malagón, } \\
\text { Isabel Garzón, Juan Carlos Castillo y Marina } \\
\text { Garzón. }\end{array}$ \\
\hline $\begin{array}{l}2001- \\
2003\end{array}$ & $\begin{array}{l}\text { Sistemas dinámicos: Una perspectiva contemporánea para la } \\
\text { enseñanza de la Física. }\end{array}$ & $\begin{array}{l}\text { Clara Inés Chaparro, Juan Carlos Orozco, Rosa } \\
\text { Pedreros, Luz Amalia Ordóñez y Primitivo } \\
\text { Belén. }\end{array}$ \\
\hline $\begin{array}{l}2001- \\
2005\end{array}$ & $\begin{array}{l}\text { Los problemas de conocimiento: Una perspectiva compleja para } \\
\text { la enseñanza de las ciencias (Segunda fase). }\end{array}$ & $\begin{array}{l}\text { Juan Carlos Orozco, Steiner Valencia, Olga } \\
\text { Méndez Núñez, Gladis Jiménez y José Pablo } \\
\text { Garzón. }\end{array}$ \\
\hline $\begin{array}{l}2004- \\
2005\end{array}$ & Los Sistemas Dinámicos y Pensamiento sistémico en el aula. & $\begin{array}{l}\text { Clara Inés Chaparro, N. Méndez, Rosa Pedreros, } \\
\text { H. Sastoque y C. Prías. }\end{array}$ \\
\hline $\begin{array}{l}2006- \\
2007\end{array}$ & $\begin{array}{l}\text { Modelación de fenómenos físicos desde la perspectiva de los } \\
\text { Sistemas Dinámicos. }\end{array}$ & $\begin{array}{l}\text { Rosa Pedreros, N. Méndez, Hugo Sastoque y } \\
\text { Sergio Galindo. }\end{array}$ \\
\hline 2007 & $\begin{array}{l}\text { La formación de maestros como práctica de traducción de } \\
\text { saberes. }\end{array}$ & $\begin{array}{l}\text { Steiner Valencia, Juan Orozco, Olga Méndez } \\
\text { Núñez, Gladys Jiménez y Juan Forero. }\end{array}$ \\
\hline 2007 & La actividad experimental en la enseñanza de las ciencias. & $\begin{array}{l}\text { María Mercedes Ayala, Francisco Malagón, } \\
\text { Sandra Sandoval y Liliana Tarazona. }\end{array}$ \\
\hline $\begin{array}{l}2006- \\
2007\end{array}$ & $\begin{array}{l}\text { Construcciones conceptuales y comprensión de la mecánica } \\
\text { cuántica }\end{array}$ & Orlando Organista y Juan Manuel Rodríguez. \\
\hline 2007 & $\begin{array}{l}\text { Proceso de formalización matemática en la concepción de } \\
\text { Maxwell }\end{array}$ & Isabel Garzón y Domingo Padilla. \\
\hline
\end{tabular}

\section{Asesoría de Proyectos}

Particularmente, el Grupo Física y Cultura ha acompañado el trabajo de investigación desarrollado por cuatro grupos de maestros del Distrito Capital, favorecidos en las convocatorias del IDEP. Además, el grupo del Experimento y las prácticas experimentales ha formulado y desarrollado dos programas de formación de docentes dirigidos a los maestros de la Educación Básica y Media del Distrito Capital.

\section{Artículos}

Pensar la escuela: ¿Políticas Educativas vs. Proyecto Educativo Institucional?. Clara I. Chaparro S., Juan Carlos Orozco, C. y Carmen Alicia Martínez. Revista Nudos y Nodos Vol. 1 N. ${ }^{\circ}$ 2. 1996.

El tiempo y los seres vivos. José Vicente Bonilla. Cuadernos sobre Historia y
Enseñanza de las Ciencias. Universidad Pedagógica Nacional. N. ${ }^{\circ}$ 3. 1996.

La mecánica analítica de Lagrange. Un estudio histórico-crítico. Bladimir Torres y María Mercedes Ayala. Cuadernos sobre Historia y Enseñanza de las Ciencias. Universidad Pedagógica Nacional. N. ${ }^{\circ}$ 3. 1996.

La temperatura, la comparación de estados de equilibrio térmico y la construcción del termómetro. Francisco Malagón, María Mercedes Ayala y Ángel Romero. Pre Impresos. Dpto. de Física. Universidad Pedagógica Nacional. N. ${ }^{\circ}$ 6, 1998.

Lo visible y lo oculto en torno al pensamiento sobre lo vivo. Steiner Valencia, Clara Chaparro y José Pablo Garzón. Cuadernos sobre Historia y Enseñanza de las Ciencias. Universidad Pedagógica Nacional. N. ${ }^{0}$ 4. 1998. 
Una experiencia sobre el uso de la historia en la enseñanza de las ciencias: Neumática. German Bautista, Luz Dary Rodríguez. Cuadernos sobre Historia y Enseñanza de las Ciencias. Universidad Pedagógica Nacional. N. ${ }^{\circ}$ 4, 1998.

¿De qué está hechas las cosas?. Margarita Vargas, Juan Carlos Orozco y Sandra Sandoval. Revista Nudos y Nodos Vol. 1 N. ${ }^{\circ}$ 6. 1999.

La construcción de la historicidad de las ciencias y la transformación de las prácticas pedagógicas. Luz Dary Rodríguez y Ángel Romero. Cuadernos sobre Historia y Enseñanza de las Ciencias. Universidad Pedagógica Nacional. N. ${ }^{\circ}$ 6. 1999.

La evaluación: ¿Obstáculo o recurso para la transformación de la Escuela. Margarita Vargas, Olga Méndez, Gladis Jiménez, Sandra Sandoval y Juan Carlos Forero. Revista TE $\Delta$. Universidad Pedagógica Nacional. N. ${ }^{0}$ 6. 1999.

Los retos culturales y la integración de saberes en la enseñanza de las ciencias. Juan Carlos Orozco. Revista Nudos y Nodos Vol. 1 N. ${ }^{\circ}$ 7. 2000.

Fenomenología de la transformación de las sustancias. Margarita Vargas, Sandra Sandoval, Érika C. y Ariza V. Revista TE $\Delta$ : Universidad Pedagógica Nacional. N. ${ }^{\circ}$ Extra. 2005.

La sistematización como estrategia de cualificación de los maestros en ciencias. Gladys Jiménez y Olga Méndez. Revista TE $\Delta$ : Universidad Pedagógica Nacional. N. ${ }^{\circ}$ Extra. 2005.

La recontextualización y resignificación de saberes como una estrategia de formación de docentes en ciencias. Steiner Valencia, Rosa Pedreros y Olga Méndez. Revista TE $\Delta$ : Universidad Pedagógica Nacional. N. ${ }^{\circ}$ Extra. 2005.
Los problemas de conocimiento una estrategia para la formación de docentes. Steiner Valencia, Olga Méndez, Juan Orozco y Gladys Jiménez. Revista TE $\Delta$ : Universidad Pedagógica Nacional. N. ${ }^{\circ}$ Extra. 2005.

La enseñanza de las ciencias y la formación de maestros. Steiner Valencia, Rosa Pedreros, Olga Méndez, Margarita Vargas, Gladys Jiménez y Sandra Sandoval. Reflexiones acerca de la investigación en Educación y Pedagogía. Universidad Pedagógica Nacional. 2007.

\section{Otras Publicaciones}

Dentro de las publicaciones no registradas se encuentran la Revista Física y Cultura, Cuadernos sobre Historia y Enseñanza de las Ciencias (ocho números). Pre-impresos (17 números).

\section{Convenios}

Cabe señalar que la actividad de investigación se ha venido acompañando con una estrategia de consolidación de comunidades académicas, lo que se traduce, entre otros aspectos, en un programa de intercambio con grupos de investigación a nivel nacional e internacional. En el caso del Departamento de Física se cuenta con dos convenios específicos con las Universidades de MilanBiccoca, Italia, y Univates de Lajeado, Rio Grande Do Sul, Brasil. Igualmente se apoya desde el Departamento el Convenio Interinstitucional con la Universidad Pedagógica Nacional Francisco Morazán de Honduras.

\section{Eventos}

Durante los últimos años se ha participado activamente en la realización del Encuentro Nacional de Enseñanza de la 
Mecánica (tres versiones), y los Lunes de la Enseñanza de la Física, que se realizan desde 1991 en el Departamento de Física de la Universidad Pedagógica Nacional. En asocio con las universidades de Antioquia, del Valle, Distrital Francisco José de Caldas y del Cauca se emprendió la realización del Congreso Nacional en Enseñanza de la Física cuya primera versión se llevó a cabo en la Universidad Pedagógica el año 2004. Se ha adelantado siete versiones del Simposio sobre la Enseñanza de las Ciencias a Nivel Básico, con la colaboración de la Corporación Escuela Pedagógica Experimental, CEPE, y la Red de cualificación de maestros RED-CEE de la Universidad Pedagógica Nacional, al inicio se contó con la parti- cipación del equipo de trabajo Anillo de matemáticas de la ADE.

\section{Bibliografía}

Documentos de Lineamientos de los Programas de Maestría en Docencia de la Física, Especialización en Docencia de las Ciencias para los Niveles Básicos y Licenciatura en Física. Departamento de Física de la Universidad Pedagógica Nacional.

Relatorías de las reuniones acerca de la investigación en el Departamento de Física de la Universidad Pedagógica Nacional.

Discusiones y elaboraciones del Grupo de Física de Procesos del Departamento de Física de la Universidad Pedagógica Nacional. 2000.

\section{Desarrollo de la investigación en el Departamento de Matemáticas, entre 1998 y 2008}

Gloria García O.*

\section{Resumen}

Este texto describe las líneas, los proyectos de investigación desarrollados, y en curso, sus productos asociados a grupos de investigación y estudio del Departamento de Matemáticas. La descripción se realiza con base en algunos de los descriptores utilizados por Colciencias.

\section{Introducción}

Este articulo describe el desarrollo de los proyectos de investigación, sus productos y los grupos de investigación y de estudio del Departamento de Matemáticas en el periodo comprendido

* Profesora del Departamento de Matemáticas de la Universidad Pedagógica Nacional. entre 1998-2008, puesto que es durante este periodo donde se visualiza el desarrollo de la investigación. Cabe destacar que este desarrollo se acompaña de las amplias actividades que despliega la comunidad académica del departamento como son: organización de eventos de carácter nacional y distrital (Encuentro de Geometría, Coloquio Distrital de matemáticas y Estadística) ; apoyo a los programas de formación inicial, y avanzada, (Licenciatura en Matemáticas, Especialización en Educación Matemática y Maestría en Docencia de la Matemática) y con la participación, cada vez más frecuente, en eventos de carácter internacional. 


\section{Grupo de Álgebra}

El grupo de Álgebra trabaja fundamentalmente en la línea Actividades Matemáticas para el desarrollo de procesos lógicos, en donde se presentan dos sublíneas:

1. Actividades matemáticas para el desarrollo de procesos lógicos en la formación inicial de profesores de matemáticas,

2. Actividades matemáticas para el desarrollo de procesos lógicos en la formación de niños talentosos en Matemáticas. En ésta desarrolla El Club de Matemáticas de la Universidad Pedagógica Nacional: un espacio para el estudio de las Matemáticas con niños y niñas de colegios distritales entre 10 y 15 años.

Proyectos de investigación

\begin{tabular}{lcc}
\hline Nombre & Año & Financiado \\
\hline $\begin{array}{l}\text { Actividades para el desarrollo } \\
\text { del pensamiento lógico: el } \\
\text { proceso de contar. }\end{array}$ & $1999-2000$ & CIUP \\
\hline $\begin{array}{l}\text { Actividades matemáticas } \\
\text { para el desarrollo de } \\
\text { procesos lógicos. El proceso } \\
\text { matemático de medir. }\end{array}$ & $2002-2004$ & CIUP \\
\hline $\begin{array}{l}\text { Actividades matemáticas } \\
\text { para el desarrollo de } \\
\text { procesos lógicos. El proceso } \\
\text { matemático de representar. }\end{array}$ & \\
\hline $\begin{array}{l}\text { Actividades matemáticas } \\
\text { para el desarrollo de } \\
\text { procesos lógicos. Los } \\
\text { procesos matemáticos de } \\
\text { razonar y ordenar. }\end{array}$ & CIUP \\
\hline
\end{tabular}

\section{Apropiación social de conocimiento}

Coordina y organiza los Encuentros de Geometría y sus Aplicaciones y los Encuentros de Aritmética.

\section{Publicaciones}

\begin{tabular}{l} 
LIBROS \\
Actividades matemáticas para el desarrollo de procesos \\
lógicos: Contar e Inducir. Carlos Luque, Edgar Páez y Lyda \\
Mora. Universidad Pedagógica Nacional. Bogotá, 2002. \\
Libro resultado de investigación. \\
\hline El proceso matemático de clasificar. Carlos Luque, Johana \\
Torres y Lyda Mora. Universidad Pedagógica Nacional. \\
Bogotá, 2004. Libro resultado de investigación. \\
Actividades matemáticas para el desarrollo de procesos \\
lógicos: clasificar, medir e invertir. Carlos Luque, Johana \\
Torres y Lyda Mora. Universidad Pedagógica Nacional. \\
Bogotá, 2005. Libro resultado de investigación. \\
Estructuras análogas a los números reales. Carlos Luque, \\
Johana Torres y Lyda Mora. Universidad Pedagógica \\
Nacional. Bogotá, 2006 . Libro resultado parcial de \\
investigación.
\end{tabular}

Fortalecimiento de la comunidad científica En la formación de comunidad científica, el grupo ha orientado diez trabajos de grado en la Licenciatura de Matemáticas y cuatro Tesis de Maestría y apoya los siguientes cursos

\begin{tabular}{ll}
\hline Cursos & Programa \\
\hline Aritmética & Licenciatura en Matemáticas \\
\hline Sistemas Numéricos & Licenciatura en Matemáticas \\
\hline Algebra Lineal & Licenciatura en Matemáticas \\
\hline Estructuras Algebraicas & Licenciatura en Matemáticas \\
\hline Teoría de Conjuntos & Licenciatura en Matemáticas \\
\hline
\end{tabular}

Miembros del Grupo

Profesores Departamento de Matemáticas: Carlos Julio Luque, Lyda Constanza Mora, José Leonardo Ángel, Jaime Fonseca, Juan Carlos Avila, Andrea Torres, Ministerio de Educación Nacional. Haydee Jiménez, estudiante maestría Matemáticas

Clasificado en Colciencias: Categoría B

\section{Grupo Didáctica de la Matemática}

Está conformado por los siguientes subgrupos:

Grupo Aprendizaje y Enseñanza de la Geometría $(Æ \cdot G)$ 
Proyectos de investigación

\begin{tabular}{lcc}
\hline Nombre & Año & Financiado \\
\hline $\begin{array}{l}\text { Desarrollo del razonamiento } \\
\text { a través de la geometría } \\
\text { euclidiana. }\end{array}$ & $2000-2002$ & CIUP \\
\hline $\begin{array}{l}\text { Geometría dinámica en la } \\
\text { formación del profesor de } \\
\text { matemáticas, desarrollada } \\
\text { en los años 2003 y 2004. }\end{array}$ & $2003-2004$ & CIUP \\
\hline $\begin{array}{l}\text { Papel de la tecnología en la } \\
\text { generación de conocimiento } \\
\text { didáctico pro parte del } \\
\text { profesor de matemáticas. }\end{array}$ & $2004-2005$ & $\begin{array}{l}\text { Colciencias } \\
\text {-IDEP- UPN }\end{array}$ \\
\hline $\begin{array}{l}\text { Geometría plana, un espacio } \\
\text { de aprendizaje }\end{array}$ & 2005 & CIUP \\
\hline $\begin{array}{l}\text { El aprendizaje de la } \\
\text { demostración en geometría } \\
\text { euclidiana con el apoyo de } \\
\text { un programa de geometría } \\
\text { dinámica, proyecto que se } \\
\text { encuentra en curso. }\end{array}$ & & \\
\hline
\end{tabular}

\section{Apropiacion social del conocimiento}

Programa de Perfeccionamiento docente a nivel distrital: Potencial didáctico del software de Geometría dinámica en el aprendizaje de la Geometría en la educación Básica y Media y Curso Ingreso Escalafón. Invitación como ponente en siete eventos internacionales.

\section{Publicaciones}

\begin{tabular}{|c|c|}
\hline Nombre & Tipo \\
\hline $\begin{array}{l}\text { La construcción de conceptos: } \\
\text { una actividad importante para } \\
\text { desarrollar razonamiento en } \\
\text { Geometría }\end{array}$ & $\begin{array}{l}\text { Revista EMA, } \\
\text { Investigación en } \\
\text { Innovación En } \\
\text { Educación Matemática, } \\
\text { UAB, v.7, No } 3\end{array}$ \\
\hline Razonamiento en Geometría. & $\begin{array}{l}\text { Revista EMA, UPNB, } \\
\text { v.6, No } 2 \text {, }\end{array}$ \\
\hline $\begin{array}{l}\text { Desarrollo del razonamiento } \\
\text { deductivo a través de la } \\
\text { Geometría Euclidiana. }\end{array}$ & Revista EMA, UPNB, v.5 \\
\hline $\begin{array}{l}\text { Cómo promover el } \\
\text { razonamiento en el aula por } \\
\text { medio de la Geometría. }\end{array}$ & Libro \\
\hline $\begin{array}{l}\text { Actividad demostrativa en la } \\
\text { formación inicial del profesor de } \\
\text { matemáticas. }\end{array}$ & Libro \\
\hline $\begin{array}{l}\text { Una visión de la actividad } \\
\text { demostrativa en geometría } \\
\text { plana para la educación } \\
\text { matemática con el uso de } \\
\text { programas de Geometría }\end{array}$ & $\begin{array}{l}\text { Revista Lecturas } \\
\text { Matemáticas. Vol. } 1\end{array}$ \\
\hline
\end{tabular}

\begin{tabular}{ll}
\hline $\begin{array}{l}\text { La demostración en la clase de } \\
\begin{array}{l}\text { Geometría: ¿puede tener un } \\
\text { papel protagónico? }\end{array}\end{array}$ & $\begin{array}{l}\text { Revista Educación } \\
\text { Matemática. Vol 17, }\end{array}$ \\
\hline $\begin{array}{l}\text { Cabri's role in the task of proving } \\
\text { within the activity of building }\end{array}$ & \\
$\begin{array}{l}\text { part of an axiomatic system. } \\
\text { International Newsletter On }\end{array}$ & http://www. \\
$\begin{array}{l}\text { The Teaching And Learning of } \\
\text { Mathematical Proof. Chipre. }\end{array}$ & \\
\hline
\end{tabular}

\section{Fortalecimiento de la comunidad científica}

En la formación de comunidad científica el grupo ha orientado 15 trabajos de grado en la Licenciatura de matemáticas, dos tesis de maestría y apoya los siguientes cursos:

\begin{tabular}{ll}
\hline Cursos & Programa \\
\hline Elementos de Geometría & Licenciatura en Matemáticas \\
\hline Geometría Plana & Licenciatura en Matemáticas \\
\hline Geometría del Espacio & Licenciatura en Matemáticas \\
\hline Matemáticas II & Maestría en Matemáticas \\
\hline \multirow{2}{*}{ Didáctica De la Geometría } & $\begin{array}{l}\text { Especialización en Educación } \\
\text { Matemática }\end{array}$ \\
\hline
\end{tabular}

Miembros del Grupo

Profesores del Departamento: Carmen Samper de Caicedo, Leonor Camargo, Armando Echeverry, Óscar Molina.

Investigadora contratada: Patricia Perry.

\section{Grupo Didáctica del Cálculo}

\section{Proyectos de investigación}

\begin{tabular}{lcc}
\hline Nombre & Año & Financiado \\
\hline $\begin{array}{l}\text { Una propuesta didáctica para } \\
\text { las nociones de función y } \\
\text { función lineal en la educación } \\
\text { Básica. }\end{array}$ & $1999-2000$ & $\begin{array}{c}\text { Colciencias } \\
\text { UPN }\end{array}$ \\
\hline $\begin{array}{l}\text { La aproximación una noción } \\
\text { básica del Cálculo: Un estudio } \\
\text { en la Educación Básica }\end{array}$ & $2000-2001$ & $\begin{array}{c}\text { Conciencias- } \\
\text { UPN }\end{array}$ \\
\hline
\end{tabular}

Análisis de obstáculos y descripción de niveles de comprensión del concepto de derivada en estudiantes de la Licenciatura en Matemática de la Universidad Pedagógica Nacional
2007-2008 CIUP 


\section{Apropiacion social del conocimiento}

Proyecto Nivelación para la Excelencia. UPN-Secretaría de Educación Distrital. 2000-2001; Proyecto de Formación y Actualización Permanente de Docentes UPN-Secretaría de Educación Distrital 1998-2003. Invitación como ponente a dos eventos internacionales.

\section{Publicaciones}

\begin{tabular}{|c|c|}
\hline Nombre & Tipo \\
\hline $\begin{array}{l}\text { Elementos para la construcción } \\
\text { de una didáctica de la función. }\end{array}$ & $\begin{array}{l}\text { Serie cuadernos de } \\
\text { investigación. }\end{array}$ \\
\hline $\begin{array}{l}\text { Situaciones de variación } \\
\text { numérica y representaciones } \\
\text { asociadas: génesis de la función } \\
\text { lineal. }\end{array}$ & $\begin{array}{l}\text { Revista Notas de } \\
\text { Matemáticas. № } 36 . \\
\text { Universidad Nacional. }\end{array}$ \\
\hline $\begin{array}{l}\text { Reforma en la enseñanza de } \\
\text { las matemáticas escolares } \\
\text { perspectivas para su desarrollo }\end{array}$ & Revista EMA, Vol 1. \\
\hline $\begin{array}{l}\text { ¿Qué hay detrás de las } \\
\text { dificultades en la comprensión } \\
\text { del número real? }\end{array}$ & $\begin{array}{l}\text { TE } \Delta \text {. Tecné, Episteme } \\
\text { y Didaxis. Facultad de } \\
\text { Ciencia y Tecnología. } \\
\text { Universidad Pedagógica } \\
\text { Nacional. № } 3\end{array}$ \\
\hline $\begin{array}{l}\text { Una aproximación } \\
\text { epistemológica, didáctica y } \\
\text { cognitiva del Cálculo. }\end{array}$ & $\begin{array}{l}\text { TE } \Delta \text {. Tecné, Episteme } \\
\text { y Didaxis. Facultad de } \\
\text { Ciencia y Tecnología. } \\
\text { № } 3 .\end{array}$ \\
\hline $\begin{array}{l}\text { Una propuesta curricular } \\
\text { para las nociones de función } \\
\text { como dependencia y la } \\
\text { proporcionalidad como función } \\
\text { lineal. }\end{array}$ & $\begin{array}{l}\text { Cuadernos Didácticos. } \\
\text { IDEP. Universidad } \\
\text { Pedagógica Nacional. }\end{array}$ \\
\hline $\begin{array}{l}\text { Variables institucionales en el } \\
\text { conocimiento profesional del } \\
\text { docente: el caso de la función. }\end{array}$ & $\begin{array}{l}\text { Revista Latinoamericana } \\
\text { de Matemática } \\
\text { Educativa. Vol. } 3 \text { № } 2\end{array}$ \\
\hline $\begin{array}{l}\text { L'inportanza delle teniche } \\
\text { di approssimazione. } \\
\text { Didattica della Matemática e } \\
\text { Rinnovamento Curricolare. }\end{array}$ & $\begin{array}{l}\text { Pitagora Editrice } \\
\text { Bologna }\end{array}$ \\
\hline $\begin{array}{l}\text { Factores relativos a la } \\
\text { identificación de funciones } \\
\text { polinómicas a partir de su } \\
\text { representación gráfica. }\end{array}$ & Revista EMA Vol 6 № 3 \\
\hline $\begin{array}{l}\text { La aproximación una noción } \\
\text { básica en el Cálculo. Un estudio } \\
\text { en la Educación Básica }\end{array}$ & Libro \\
\hline
\end{tabular}

\section{Fortalecimiento de la comunidad científica}

En la formación de comunidad científica el grupo ha orientado cinco tesis de maestría; apoya los siguientes cursos:

\begin{tabular}{ll}
\hline Cursos & Programa \\
\hline Cálculo Diferencial & Licenciatura en Matemáticas \\
\hline $\begin{array}{l}\text { Didáctica del Cálculo } \\
\text { Diseño y desarrollo } \\
\text { curricular }\end{array}$ & \begin{tabular}{l} 
Matemática \\
\hline Matemáticas I
\end{tabular} \\
\hline
\end{tabular}

\section{Integrantes}

Gloria García O, Hernán Díaz, Luis E Espitia, Claudia Salazar, Mauricio Bautista, José Torres y Edwin Carranza

\section{Grupo evaluación en Matemáticas Proyectos de investigación}

\begin{tabular}{lcc}
\hline Nombre & Año & Financiado \\
\hline $\begin{array}{l}\text { Modelos y prácticas de } \\
\text { evaluación en Matemáticas. El } \\
\text { caso del campo multiplicativo } \\
\text { en la Educación Básica. }\end{array}$ & $2002-2004$ & Colciencias \\
\hline $\begin{array}{l}\text { El saber didáctico en la } \\
\text { formación inicial del profesor } \\
\text { de matemáticas: las practicas } \\
\text { de evaluación en la clase de }\end{array}$ & $2004-2005$ & CIUP \\
matemáticas & & \\
\hline $\begin{array}{l}\text { Desarrollo curricular y } \\
\text { profesional de profesores de } \\
\text { matemática en contextos } \\
\text { de trabajo colaborativo y de } \\
\text { investigación sobre la práctica }\end{array}$ & En curso & \\
\hline
\end{tabular}

\section{Apropiacion social del conocimiento:}

Participa en el Grupo Estándares Básicos en Matemáticas; Comité Nacional sobre las Competencias matemáticas. Ministerio de Educación Nacional.

\section{Publicaciones}

\begin{tabular}{ll}
\hline Nombre & Tipo \\
\hline $\begin{array}{l}\text { La evaluación de las competencias } \\
\text { en Matemáticas y el currículo: un } \\
\text { problema de coherencia y consistencia }\end{array}$ & Capítulo libro \\
\hline $\begin{array}{l}\text { Prácticas de evaluación en las clases de } \\
\text { matemáticas en la Educación Básica. }\end{array}$ & Libro \\
\hline $\begin{array}{l}\text { Análisis curricular Área de } \\
\text { matemáticas. Segundo Estudio }\end{array}$ & Capítulo libro \\
$\begin{array}{l}\text { Regional Comparativo y Explicativo } \\
\text { Estándares Básicos de competencias } \\
\text { en matemáticas. Potenciar el }\end{array}$ & \\
$\begin{array}{l}\text { pensamiento matemático ¡un reto } \\
\text { escolar! }\end{array}$ & Capítulo libro \\
\hline $\begin{array}{l}\text { Un análisis didáctico de la Evaluación } \\
\text { en las aulas de matemáticas. }\end{array}$ & Capítulo libro \\
\hline
\end{tabular}


Fortalecimiento de la comunidad científica

En la formación de comunidad científica el grupo ha orientado un trabajo de grado en la Licenciatura de Matemáticas, cuatro tesis de maestría, y apoya los siguientes cursos:

\begin{tabular}{ll}
\hline Cursos & Programa \\
\hline Evaluación en matemáticas & Licenciatura en Matemáticas \\
\hline Seminario de Investigación I & $\begin{array}{l}\text { Maestría Docencia de la } \\
\text { Matemática }\end{array}$ \\
\hline Didáctica de la matemática & Licenciatura en Matemáticas \\
\hline
\end{tabular}

\section{Integrantes}

Gloria García, Gabriel Mancera y Francisco Camelo.

Clasificación de Colciencias: Categoría A.

\section{Grupo educación estadística}

Formalmente, la línea de investigación en Educación Estadística nace en el año 2005 con la realización de un par de Proyectos de Facultad.

\section{Proyectos de investigación}

\begin{tabular}{lcc}
\hline Nombre & Año & Financiado \\
\hline $\begin{array}{l}\text { Conocimiento estadístico y } \\
\text { probabilístico de profesores de }\end{array}$ & 2006 & CIUP \\
$\begin{array}{l}\text { educación básica y media en curso. } \\
\text { educicion }\end{array}$ & & \\
\hline
\end{tabular}

\section{Apropiacion social del conocimiento:}

Organizó, junto con la Universidad Distrital Franciso José de Caldas y la Universidad Nacional de Colombia, el Primer Encuentro Nacional en Educación Estadística, ENAES.

\section{Publicaciones}

\begin{tabular}{lc}
\hline Nombre & Tipo \\
\hline $\begin{array}{l}\text { La cuerda de Bertrand: una paradoja } \\
\text { sobre asignación de probabilidades en }\end{array}$ & Memorias \\
$\begin{array}{l}\text { Fernández } \\
\text { Consideraciones acerca de la educación } \\
\text { estadística en Colombia. }\end{array}$ & Memorias \\
\hline Medidas de localización y dispersión. & Memorias
\end{tabular}

Fortalecimiento de la comunidad científica

Tiene a su cargo los siguientes cursos:

\begin{tabular}{ll}
\hline Cursos & Programa \\
\hline Estadistica y probabilidad & Licenciatura en Matemáticas \\
\hline Métodos estadísticos & Licenciatura en Matemáticas \\
\hline Seminario de estadistica & Licenciatura en Matemáticas \\
\hline Educación estadistica & $\begin{array}{l}\text { Especialización en Educación } \\
\text { Matemática }\end{array}$ \\
\hline Matemáticas I & Maestría en Matemáticas \\
\hline
\end{tabular}

\section{Integrantes:}

Felipe Fernandez y

Benjamín Sarmiento.

Registrado en: Colciencias

\section{Grupo Fractales}

Formalmente el grupo nace en el año 2005.

Proyectos de investigación

\begin{tabular}{lcc}
\hline Nombre & Año & Financiado \\
\hline $\begin{array}{l}\text { El concepto de dimensión } \\
\text { como potencial didáctico }\end{array}$ & & \\
y su incidencia en el & & \\
aprendizaje de la Geometría & & \\
$\begin{array}{l}\text { Fractal en estudiantes de la } \\
\text { Licenciatura en Matemáticas }\end{array}$ & $2006-2007$ & CIUP \\
de la Universidad Pedagógica & & \\
Nacional: una experiencia & & \\
de aula. & &
\end{tabular}

Fortalecimiento de la comunidad científica En la Formación de comunidad científica el grupo ha orientado 4 trabajos de grado en la Licenciatura de Matemáticas y una tesis de maestría.

\section{Integrantes:}

Profesores departamento de Matemáticas: Jorge Édgar Páez, Claudia Orjuela, Clara Emilse Rojas. Investigador contratado: William Fernando Estrada. 


\section{Grupo Rutas pedagógicas en la formación del profesor de Matemáticas}

\section{Proyectos de investigación}

\begin{tabular}{lcc}
\hline Nombre & Año & Financiado \\
\hline $\begin{array}{l}\text { Rutas pedagógicas en la formación } \\
\text { de Licenciados en matemáticas } \\
\text { de la Universidad Pedagógica } \\
\text { Nacional. }\end{array}$ & 2004 & CIUP \\
\hline $\begin{array}{l}\text { Rutas de aprendizaje en la } \\
\text { formación de Licenciados en } \\
\text { matemáticas de la Universidad }\end{array}$ & 2005 & CIUP \\
$\begin{array}{l}\text { Pedagógica Nacional. } \\
\text { Conocimiento profesional del }\end{array}$ & & \\
$\begin{array}{l}\text { estudiante de Licenciatura en } \\
\text { matemáticas: una mirada a través } \\
\text { de su práctica docente. }\end{array}$ & 2006 & CIUP \\
\hline $\begin{array}{l}\text { La reflexión sistemática sobre } \\
\text { la práctica docente como } \\
\text { herramienta para la formación del } \\
\text { Licenciado en matemáticas. }\end{array}$ & 2007 & CIUP \\
\hline
\end{tabular}

\section{Integrantes}

Profesores Departamento de Matemáticas: Claudia Salazar, Luisa Andrade,
Fortalecimiento de la comunidad científica Ha orientado dos trabajos de grado de la Licenciatura en Matemáticas y apoya el siguiente curso:

\begin{tabular}{ll}
\hline Cursos & Programa \\
\hline Proyecto de aula & Licenciatura en Matemáticas \\
\hline $\begin{array}{ll}\text { Publicaciones } \\
\text { Nombre }\end{array}$ & Tipo \\
\hline $\begin{array}{l}\text { Rutas pedagógicas en la formación } \\
\text { de Licenciados en matemáticas: } \\
\text { dificultades para su transformación. }\end{array}$ & $\begin{array}{l}\text { Revista Tecné, } \\
\text { Episteme y Didaxis, }\end{array}$, No 21
\end{tabular}

\begin{tabular}{ll}
\hline $\begin{array}{l}\text { Conocimiento profesional del } \\
\text { estudiante de Licenciatura en } \\
\text { matemáticas: }\end{array}$ & $\begin{array}{l}\text { Encuentro Nacional } \\
\text { de Instituciones }\end{array}$ \\
$\begin{array}{l}\text { una mirada a través de su práctica } \\
\text { docente en el }\end{array}$ & $\begin{array}{l}\text { Formadoras de } \\
\text { formadores. }\end{array}$ \\
\hline $\begin{array}{l}\text { Conocimiento profesional del } \\
\text { estudiante de Licenciatura en } \\
\text { Matemáticas: una mirada a través de } \\
\text { su práctica docente }\end{array}$ & Memorias \\
\end{tabular}

Cecilia Leguizamón de Bernal, Nubia Soler, José Torres, Luis Espitia.

\section{Diez años de investigación en el Departamento de Química}

Como lo destacan las mismas investigaciones en Didáctica de las ciencias, una de las principales características del profesional de la docencia de hoy es su compromiso con la investigación de los procesos de enseñanza-aprendizaje, lo que conlleva al mejoramiento permanente de la calidad de la educación. Docencia e investigación son dos partes de un todo

\footnotetext{
* Profesora del Departamento de Química de la
} Universidad Pedagógica Nacional. y para lograrlo, la Univesidad Pedagógica Nacional y el Departamento de Química tienen su concepción de investigación la cual intenta ser implementada desde el proyecto curricular experimental de Licenciatura en Química.

En el Proyecto Curricular Experimental para la formación de Licenciados en Química (2000,21), la investigación se concibe como un espacio para que el profesorado, el estudiantado y/o investigadores del Departamento se comprometan a desarrollar la pedagogía 
y la didáctica de las ciencias en general y de la Química en particular; así, la investigación en el Departamento de Química se articula desde los grupos de investigación con sus líneas y proyectos de investigación, dirigidos por uno o varios profesores que definen los marcos conceptuales y procedimentales para el desarrollo de sus proyectos.

En la comunidad académica de la Universidad Pedagógica Nacional la investigación se concibe como una construcción sociocultural, y se entiende como un proceso creativo y académico de producción, innovación, originalidad, adaptación, difusión y socialización del conocimiento, orientado a comprender, explicar, contrastar, proponer y buscar solución a problemas propios de teorías y de las prácticas que le competen de acuerdo con sus proyectos y objetivos científicos, pedagógicos didácticos (http://www.pedagógica.edu.co).

Describir la investigación en el Departamento de Química en los últimos diez años (1997-2007), significa hacer un reconocimiento al proceso de sistematización de los procesos investigativos iniciados, ante todo, por el Grupo de investigación IREC y a los aportes de los demás grupos, entre ellos: La Didáctica y sus ciencias, Alternativas para enseñanza de las ciencias naturales, Estilos pedagógicos, a la línea de investigación Desarrollo de habilidades de pensamiento y enseñanza de las ciencias, y al grupo interinstitucional y Ciencia, creencias y acciones, donde participan profesores del Departamento de Química.

Caracterizar la investigación en el Departamento de Química significa caracterizar los grupos de investigación. Veamos sus principales aportes.

\section{El Grupo IREC}

Como se mencionó en un párrafo anterior, el Grupo IREC llevó a cabo el proceso de sistematización de las investigaciones realizadas, al presentar el documento titulado Representaciones y conceptos científicos. Un programa de investigación de 1994. A partir de su contenido, se empezaron a orientar los trabajos de grado y a los estudiantes de maestrías que se inscribían con los proferores Rómulo Gallego Badillo o con Royman Pérez Miranda.

La primera investigación asumida por los directores del Grupo se adelantó durante los años 1995 y 1996, con la cohorte de profesores en formación avanzada de esos años, inscritos en el Programa de Maestría en Docencia de la Química. Los resultados fueron publicados en unas memorias de investigación (Gallego Badillo y Pérez Miranda, 2000), de las cuales derivó un artículo publicado en una revista especializada (Gallego Badillo y Pérez Miranda 2002). En el año 2000 se desarrolló un proyecto de investigación evaluado, aprobado y financiado por la Universidad Pedagógica Nacional, cuyos resultados fueron publicados en una revista especializada (Pérez Miranda y Gallego Badillo, 2006). De la misma manera, en 2001 se adelantó una investigación, también evaluada, aprobada y financiada por la Universidad que se presentó como comunicación oral en el VI Congreso Internacional sobre investigación en Didáctica de las Ciencias (Gallego Badillo y Torres de Gallego, 2001) y un trabajo sobre la evolución de las concepciones de la Química en estudiantes de la Universidad Pedagógica Nacional que se presentó en una comunicación oral (Pérez Miranda y Gallego Badillo, 2001). 
En el año 2002 y 2003 se desarrollaron dos proyectos de investigación en torno a los fundamentos de la formación inicial de profesores en Colombia remitidos a aquellos programas que habían obtenido la acreditación previa por parte del Comité Nacional de Acreditación, CNA, (Gallego Badillo, Pérez Miranda y Torres de Gallego, 2004; Pérez Miranda, Gallego Badillo, Torres de Gallego y Amador Rodríguez, 2004). En estos años, también se desarrollaron dos proyectos de investigación en relación con la construcción de competencias, con estudiantes de educación media, cuyos resultados fueron publicados en unas memorias de investigación y en un artículo en una revista especializada (Pérez Miranda, Gallego Badillo, Torres de Gallego y Cuéllar Fernández, 2004).

En 2004 se inicia, por parte del Grupo IREC un proyecto cuyo objetivo fue hacer un estudio comparativo entre los programas de formación de profesores de la Universidad Pedagógica Nacional y la Facultad de Ciencias de la Universidad Estatal Paulista, sede Baurú, Brasil, Esta investigación tuvo un segundo proyecto en 2006 en el que esos estudios comparativos se extendieron a las universidades de Buenos Aires, la Pontificia Universidad Católica de Chile y la Pontificia Universidad Católica de Valparaíso, que se amplió a la Universidad de San Martín (Argentina), a la Universidad Metropolitana de Ciencias de la Educación, de Santiago de Chile y a la Universidad de los Andes de Venezuela. De cada uno de estos proyectos se presentaron los correspondientes informes finales a la División de Gestión de Proyectos- Centro de Investigaciones de la Universidad Pedagógica Nacional, DGP-CIUP y en la actualidad se elaboró una memoria de investigación que se ha sometido a la Facultad de Ciencia y Tecnología para su evaluación y posible publicación. En la Vigencia 2005, la Universidad evaluó y aprobó un proyecto de investigación inicialmente titulado El aprendizaje del oficio de enseñar ciencias, del cual se entregó un informe final. Sus resultados parciales fueron presentados ante la Comunidad Internacional de investigadores en didáctica de las ciencias celebrado en Granada, España, ese mismo año. Los resultados finales dieron pie para un artículo que se publicó en una revista electrónica (Gallego Badillo, Pérez Miranda y Torres de Gallego, 2006).

El Grupo IREC, clasificado hoy en la categoría A por Colciencias, se ha caracterizado por hacer aportes a la discusión en didáctica de las ciencias que han sido publicados en revistas especializadas (Gallego Badillo, 2004, y Gallego Torres y Gallego Badillo, 2006; Gallego Torres, Gallego Badillo y Pérez Miranda, 2006; Gallego Badillo, Pérez Miranda y Gallego Torres, 2006).

Dentro de los libros publicados por el grupo se destacan los presentados en la Tabla 1 y los artículos y ponencias se presentan en la Tabla 2. 
Tabla 1. Libros publicados por el grupo IREC.

\begin{tabular}{|c|c|c|c|}
\hline Nombre del libro & Autores & Año & Editorial \\
\hline $\begin{array}{l}\text { El problema del cambio en las } \\
\text { concepciones epistemológicas, } \\
\text { pedagógicas y didácticas. }\end{array}$ & Rómulo Gallego Badillo y Royman Pérez Miranda. & 1999 & $\begin{array}{l}\text { Universidad } \\
\text { Pedagógica } \\
\text { Nacional. }\end{array}$ \\
\hline $\begin{array}{l}\text { La formación inicial de profesores de } \\
\text { ciencias en Colombia. Contrastación de } \\
\text { fundamentos. }\end{array}$ & $\begin{array}{l}\text { Rómulo Gallego Badillo, Royman Pérez Miranda, } \\
\text { Luz Nery Torres de Gallego y Rafael Yecid Amador } \\
\text { Rodríguez. }\end{array}$ & 2004 & $\begin{array}{l}\text { Universidad } \\
\text { Pedagógica } \\
\text { Nacional. }\end{array}$ \\
\hline $\begin{array}{l}\text { Las competencias interpretar, } \\
\text { argumentar y proponer en química: Un } \\
\text { problema pedagógico y didáctico. }\end{array}$ & $\begin{array}{l}\text { Royman Pérez Miranda, Rómulo Gallego Badillo, } \\
\text { Luz Nery Torres de Gallego y Luigi Cuéllar } \\
\text { Fernández. }\end{array}$ & 2004 & $\begin{array}{l}\text { Universidad } \\
\text { Pedagógica } \\
\text { Nacional. }\end{array}$ \\
\hline La construcción escolar de las ciencias. & $\begin{array}{l}\text { Rómulo Gallego Badillo, Royman Pérez Miranda y } \\
\text { Luz Nery Torres de Gallego. }\end{array}$ & 2005 & $\begin{array}{l}\text { Cooperativa Editorial } \\
\text { Magisterio. }\end{array}$ \\
\hline $\begin{array}{l}\text { La didáctica de las ciencias de la } \\
\text { Naturaleza. Una disciplina conceptual y } \\
\text { metodológicamente fundamentada. }\end{array}$ & $\begin{array}{l}\text { Adriana Patricia Gallego Torres y Rómulo Gallego } \\
\text { Badillo. }\end{array}$ & 2006 & $\begin{array}{l}\text { Cooperativa Editorial } \\
\text { Magisterio. }\end{array}$ \\
\hline
\end{tabular}

Tabla 2. Artículos y ponencias publicados por el grupo IREC.

Título del artículo, pombre de la revista, memorias del congreso o proyectos de investigación

\begin{tabular}{|c|c|}
\hline $\begin{array}{l}\text { El problema del cambio en las concepciones } \\
\text { epistemológicas, pedagógicas y didácticas. }\end{array}$ & Bogotá, Universidad Pedagógica Nacional. 2000 \\
\hline $\begin{array}{l}\text { Las competencias interpretar, argumentar y } \\
\text { proponer en ciencias. Un problema pedagógico y } \\
\text { didáctico. }\end{array}$ & $\begin{array}{l}\text { Enseñanza de las ciencias, VI Congreso internacional sobre enseñanza } \\
\text { de las ciencias. Número Extra. } 2001\end{array}$ \\
\hline $\begin{array}{l}\text { Evolución en las concepciones sobre Química en } \\
\text { estudiantes de licenciatura. }\end{array}$ & $\begin{array}{l}\text { Enseñanza de las ciencias, VI Congreso internacional sobre enseñanza } \\
\text { de las ciencias. Número Extra. } 2001\end{array}$ \\
\hline $\begin{array}{l}\text { El problema del cambio en las concepciones de } \\
\text { estudiantes de formación avanzada. }\end{array}$ & Enseñanza de las ciencias, 20(3), 401-414. 2002 \\
\hline $\begin{array}{l}\text { Las competencias interpretar, argumentar y } \\
\text { proponer en Química. Un problema pedagógico y } \\
\text { didáctico. }\end{array}$ & $\begin{array}{l}\text { Memorias de investigación. Bogotá, Universidad Pedagógica Nacional. } \\
2004\end{array}$ \\
\hline $\begin{array}{l}\text { La formación inicial de profesores de ciencias en } \\
\text { Colombia. Contrastación de fundamentos. }\end{array}$ & $\begin{array}{l}\text { Memoria de investigación. Bogotá, Universidad Pedagógica Nacional. } \\
2004\end{array}$ \\
\hline $\begin{array}{l}\text { Formación inicial de profesores de ciencias en } \\
\text { Colombia: Un estudio a partir de programas } \\
\text { acreditados. }\end{array}$ & Ciência \& Educação, 10, 2, 219-234. 2004 \\
\hline
\end{tabular}

Formación inicial de profesores de ciencias en Colombia: un estudio a partir de programas acreditados.

\begin{tabular}{|c|c|}
\hline $\begin{array}{l}\text { El papel de las "prácticas docentes" en la formación } \\
\text { inicial de profesores de ciencias. }\end{array}$ & $\begin{array}{l}\text { Revista Electrónica Enseñanza de las Ciencias, Vol. 5, No. 3, Art. 6. En } \\
\text { línea: } \\
\text { http://www.saum.uvigo.es./reec } 2006 .\end{array}$ \\
\hline $\begin{array}{l}\text { Un orden histórico didáctico para la química. Una } \\
\text { experiencia investigativa en ecuación secundaria. }\end{array}$ & Educación Química, 18 (1) pp. 114-122. 2007 \\
\hline $\begin{array}{l}\text { ¿Qué versión de Ciencia se enseña en el aula? } \\
\text { Sobre los modelos científicos y la didáctica de la } \\
\text { modelación. }\end{array}$ & Educación y Educadores, 9, 1. 2006 \\
\hline $\begin{array}{l}\text { A construção de modelos na formação inicial e } \\
\text { continuada de professores de Química. }\end{array}$ & $\begin{array}{l}\text { En Nardi, R e P. M. Almeida, M. S. (Organizadores) Analogías, leituras e } \\
\text { Modelos no ensino da Ciência, Sao Paulo, Escrituras, pp. 141-159. } 2006\end{array}$ \\
\hline $\begin{array}{l}\text { Concepciones sobre Pedagogía y Didáctica en un } \\
\text { grupo de docentes. Informe de investigación. }\end{array}$ & Revista Educación y Pedagogía, 18, 44, 129-137. 2006 \\
\hline
\end{tabular}

El compromiso establecido en el documento de 1994 exigió que el Grupo pusiera a discusión de los interesados los proyectos histórico-epistemológicos acerca de las ciencias y su didáctica; proyectos estos cuyos resultados vieron la luz en diversas publicaciones. 


\section{Grupo Didáctica y sus ciencias}

El grupo de investigación Didáctica y sus ciencias es liderado actualmente por la doctora Yolanda Ladino y está integrado por profesores de planta del Departamento, profesores catedráticos y estudiantes de Licenciatura en Química y de Maestría en Docencia de la Química.

En el contexto de los programas académicos del Departamento de Química de la Universidad Pedagógica Nacional, El grupo busca que los profesores en formación o profesionales de ciencias en general, conozcan no solo la disciplina que enseñan, sino también que adquieran una visión detallada de la didáctica de la misma, en este caso la química. En el grupo se orientan dos líneas de investigación: incorporación de la educación ambiental al currículo de ciencias y la evaluación como una forma de aprender en Química (CIUP, 2007). Cada una de las líneas esboza algunos problemas que pretende resolver fortaleciendo la parte didáctica y disciplinar de la Química. Es decir, analizar la problemática de la enseñanza de la química considerando entre otros aspectos didácticos las ideas previas, las concepciones alternativas, la resolución de problemas, los trabajos prácticos, el diseño de unidades didácticas y el problema de la evaluación.

Las principales preguntas de investigación planteadas por el grupo son:

¿Generar espacios y metodologías para pensar, reflexionar y discutir en- torno a los problemas didácticos de la enseñanza y el aprendizaje de la Química, aporta en la construcción colectiva de dicha disciplina? ¿Fortalecer la investigación disciplinar, para a partir de ella analizar los conceptos asociados y establecer las propuestas didácticas que favorezcan la enseñanza y el aprendizaje de los conceptos implicados, hace profesionales más competentes? ¿Incentivar en los futuros docentes de la Química, y a los ya profesionales en ciencias, para que empleen la investigación y la innovación didáctica, de su disciplina, en sus cursos habituales, contribuye a mejorar la calidad en los procesos de enseñanza y aprendizaje que llevan acabo en el aula de clase?

En la actualidad, el grupo presenta dos proyectos CIUP-UPN vigentes: La evaluación metacognitiva de competencias como una herramienta para la autonomía (CIUP-DQU-021-07), y Desarrollo de competencias científicas e investigativas para la construcción de conceptos en Química a partir de fenómenos catalíticos (CIUP-DQU-023-07).

El grupo presenta publicaciones en las revistas: Sociedad Química de México, Journal Of Thermal Analysis And Calorimetry, TEA: Tecné, Episteme Didaxis, Estudios en Pedagogía y Didáctica, Revista Química de la universidad de los Andes, Enseñanza de las Ciencias, Revista Itinerario Educativo, entre otras, como se aprecia en la Tabla 3.

Tabla 3. Algunos de los artículos y ponencias publicados por el grupo Didáctica y sus ciencias

\begin{tabular}{ll}
\hline Título del artículo, ponencia o proyecto & $\begin{array}{l}\text { Nombre de la revista, de las memorias del congreso o } \\
\text { de proyectos de investigación }\end{array}$ \\
\hline $\begin{array}{l}\text { Concepciones docentes sobre evaluación y su visión de } \\
\text { ésta como una forma de aprender en ciencias. }\end{array}$ & $\begin{array}{l}\text { Actas de las VII Jornadas de Enseñanza Universitaria de la } \\
\text { Química, págs. 200 - 200. 2006. }\end{array}$ \\
\hline $\begin{array}{l}\text { Construcción de conceptos alrededor de conceptos } \\
\text { químicos: una propuesta metodológica de laboratorio } \\
\text { como investigación. }\end{array}$ & $\begin{array}{l}\text { Revista TEs: Tecné, Episteme y Didaxis. Volumen Extra, } \\
\text { p. 194-195. 2005. }\end{array}$ \\
\hline
\end{tabular}




\begin{tabular}{|c|c|}
\hline El currículo: la opción por la excelencia; & Estudios en Pedagogía y Didáctica. 2. 1. p. 14-22. 1997. \\
\hline $\begin{array}{l}\text { En la formación del profesorado ¿Por qué evaluar al } \\
\text { profesor? }\end{array}$ & $\begin{array}{l}\text { Revista TEA: Tecné, Episteme y Didaxis. No. Extra. p. } \\
\text { 118-120. 2003. }\end{array}$ \\
\hline $\begin{array}{l}\text { Enseñanza y aprendizaje por investigación de los } \\
\text { conceptos Reacción y Ecuación Química }\end{array}$ & $\begin{array}{l}\text { Revista TEA: Tecné, Episteme y Didaxis. Volumen Extra p. } \\
\text { 163-164. } 2005\end{array}$ \\
\hline La didáctica de la Química, una disciplina emergente & $\begin{array}{l}\text { Revista TEA. Tecné, Episteme y Didaxis. } 15 \text { p. 76-87. } \\
2004 .\end{array}$ \\
\hline $\begin{array}{l}\text { La importancia del concepto mol en el desarrollo practico } \\
\text { de la Química. }\end{array}$ & $\begin{array}{l}\text { Revista TEA: Tecné, Episteme y Didaxis. Volumen Extra. p. } \\
\text { 158-160. } 2005\end{array}$ \\
\hline $\begin{array}{l}\text { La resolución de problemas como estrategia didáctica en la } \\
\text { enseñanza de métodos potenciométricos incrementales. }\end{array}$ & Apuntes Pedagógicos. Fascículo 31. p. 1-94. 2004 \\
\hline Miniproyectos como alternativa de aprendizaje en Química & $\begin{array}{l}\text { Actas de las VII Jornadas de Enseñanza Universitaria de la } \\
\text { Química. Pp. } 120 \text { - 124. } 2006\end{array}$ \\
\hline
\end{tabular}

\section{Desarrollo de habilidades de pensamiento y enseñanza de las ciencias}

Desarrollo de habilidades de pensamiento y enseñanza de las ciencias, más que un grupo es una línea de investigación liderada por el Dr. Pedro Nel Zapata.

Esta línea un esfuerzo por contribuir a plantear posibles soluciones desde el ámbito educativo al bajo desempeño intelectual de los estudiantes.

El objetivo general de la línea es desarrollar habilidades de pensamiento que incidan sobre los niveles de aprendizaje que alcanzan los estudiantes en cursos de ciencias y, en general, en las demás áreas de formación que componen el currículo y el plan de estudios. Se busca, entre otros aspectos, que el aprendizaje sea más significativo y duradero y posibilite al sujeto la adecuada toma de decisiones y la resolución de problemas no solo en los ámbitos escolares sino también extraescolares.

A través de las investigaciones adelantadas se procura la estimulación de los procesos de pensamiento para la construcción de estructuras cognoscitivas. Dichos procesos incluyen la inducción, la deducción, el pensamiento analógico, hipotético, analítico-sintético, creativo, estratégico, directivo y ejecutivo para el manejo de información y la adquisición de conocimiento.

Las publicaciones de la línea se presentan en la Tabla 4.

Tabla 4. Publicaciones de la línea Desarrollo de habilidades de pensamiento y enseñanza de las ciencias

\begin{tabular}{|c|c|}
\hline Título del artículo, ponencia o proyecto & $\begin{array}{l}\text { Nombre de la revista, de las memorias del } \\
\text { congreso o de proyectos de investigación }\end{array}$ \\
\hline $\begin{array}{l}\text { Una aplicación de la teoría de conjuntos, la lógica de proposiciones } \\
\text { y la teoría de grafos al análisis de mapas conceptuales. }\end{array}$ & $\begin{array}{l}\text { Revista TE } \Delta \text {, Tecné, episteme y didaxis. 10. p. 79- } \\
\text { 891. 2001. }\end{array}$ \\
\hline Concepciones y prácticas de evaluación de los profesores. & Revista Actualidades pedagógicas. 42. p. 73-86. 2002. \\
\hline La evaluación de los aprendizajes. & Revista de Cultura. CONACED. 20. p. 59-68. 2002. \\
\hline $\begin{array}{l}\text { Desarrollo de Habilidades de Pensamiento y Enseñanza de las } \\
\text { Ciencias. }\end{array}$ & $\begin{array}{l}\text { VII Congreso Internacional sobre Investigación en la } \\
\text { Didáctica de las Ciencias. Granada, España. № Extra. } 2005 .\end{array}$ \\
\hline $\begin{array}{l}\text { Desarrollo de habilidades de pensamiento y metacognición en } \\
\text { ciencias. }\end{array}$ & $\begin{array}{l}\text { Il Congreso sobre Formación de profesores en Ciencias. } \\
\text { Bogotá. } 2005 .\end{array}$ \\
\hline $\begin{array}{l}\text { Desarrollo de habilidades de pensamiento y enseñanza de las } \\
\text { ciencias. }\end{array}$ & $\begin{array}{l}\text { En Revista de investigación 5. Universidad de La Salle. } \\
2005 .\end{array}$ \\
\hline $\begin{array}{l}\text { Los procesos de adquisición de conocimiento en la didáctica de } \\
\text { la ciencia química en la educación superior. }\end{array}$ & $\begin{array}{l}\text { Revista TE } \Delta, \text { Tecné, episteme y didaxis. 19. p. 5-21. } \\
2006\end{array}$ \\
\hline
\end{tabular}




\section{Grupo alternativas para la enseñanza de las ciencias naturales, Alternaciencias}

Buscando construir marcos teóricos y metodológicos alternativos para la enseñanza de las ciencias naturales, el grupo de investigación ALTERNACIENCIAS comenzó a construir trabajos de investigación relacionados con las prácticas pedagógicas de profesores en formación inicial (PFI) especialmente de química y biología, de acuerdo con esto, se construyeron dos trabajos de grado sobre la enseñanza de las ciencias naturales en escuelas de educación básica primaria (Martínez y Loboa, 2002; Castillo y Martínez, 2003).

El primer trabajo construido por Martínez y Loboa (2002) generó una propuesta para la enseñanza de las ciencias con base en: presupuestos epistemológicos de la teoría Crítica (Habermas, 1990; Carr y Kemmis, 1986), presupuestos didácticos del Constructivismo (Porlan, 1995, 1997, 1998) y presupuestos pedagógicos propios de la Pedagogía Crítica (Freire, 1972; Giroux, 1990). En su conjunto la propuesta tenía como objetivo desarrollar la enseñanza de las ciencias como una actividad social y cultural, que desmitificara la ciencia como un conocimiento incuestionable y exclusivo de los científicos.

Por su parte, el trabajo de Castillo y Martínez (2003) retomó los planteamientos teóricos expuestos en la propuesta de Martínez y Loboa (2002) para el diseño e implementación de una unidad didáctica que posibilitó en estudiantes de educación básica primara vivenciar procesos significativos de construcción de conocimiento en el campo de las Ciencias Naturales $(\mathrm{CN})$.
Retomando los trabajos que fueron expuestos anteriormente, se constituyó en la Facultad de Ciencia y Tecnología de la Universidad Pedagógica Nacional una cátedra pedagógica electiva de formación de maestros en contextos vulnerables (Martínez et ál., 2006a) promoviendo la construcción de experiencias pedagógicas y didácticas en diferentes áreas del conocimiento (Física, Química, Matemáticas, Biología, Psicopedagogía, Ciencias Sociales, Educación especial y Artes) fundamentadas en la perspectiva de derecho y en la comprensión compleja de la realidad desde la perspectiva de la Investigación-Acción (IA).

Además, se desarrolló un proyecto de investigación de la Facultad de Ciencia y Tecnología (Martínez et ál., 2006b) que logró concretar un modelo de Enseñanza de las Ciencias Naturales en contexto de vulnerabilidad que enfatiza estructuralmente no sólo en los espacios didácticos y sus interrelaciones, sino que hace especial énfasis en el estilo pedagógico de diálogos, construcción compartida de temas (problemas de conocimiento), procesos de acuerdos para la concreción de los mismos y articulación de los conocimientos de los profesores y de los estudiantes, con los saberes de la comunidad (padres de familia).

Teniendo en cuenta la experiencia del grupo constituida hasta entonces -año 2006- y partiendo de la intención de construir un programa de investigación que contribuyera a la formación inicial y continua de profesores de ciencias, en particular de química, se constituyeron dos líneas de investigación: 1) Enseñanza de las Ciencias en Contexto Ciencia, Tecnología, Sociedad y Ambiente (CTSA), 
y 2) Didáctica de los Contenidos curriculares en Química.

Constituidas estas líneas de investigación y con la producción académica de los miembros del grupo de investigación, se participó en la convocatoria de medición y reconocimiento de grupos realizada por Colciencias en el segundo semestre de 2006, obteniendo el reconocimiento respectivo en la categoría C.

Las dos líneas adoptaron los siguientes cuestionamientos que orientan la constitución de proyectos de investigación, dirección de trabajos de grado, tesis de maestría y otros trabajos que puedan generarse en su desarrollo:

¿Qué tipo de conocimiento, de imagen de ciencia e investigación promueve y privilegia la escuela? ¿Cuáles son los retos del profesor de ciencias en la sociedad y la escuela contemporánea?
¿Mediante qué estrategias didácticas y pedagógicas es posibles construir una imagen de ciencia crítica y pertinente a diversos contextos socioculturales del país? ¿Cuáles son los modelos y las concepciones didácticas del profesorado y sus implicaciones en su desarrollo profesional a nivel inicial y permanente en torno al diseño curricular? ¿Qué características deben tener los contenidos de enseñanza y cómo se deben organizar en torno al conocimiento escolar? ¿Cómo diseñar los currículos de los espacios académicos o "asignaturas" en torno a tramas conceptuales evolutivas cada vez más complejas?

De acuerdo con esto, el grupo ha publicado en relación con la línea Enseñanza de las Ciencias en Contexto Ciencia, Tecnología, Sociedad y Ambiente (CTSA) lo enunciado en la Tabla 5:

Tabla 5. Trabajos publicados en la línea 1 por el grupo Alternaciencias

\begin{tabular}{|c|c|}
\hline Título del artículo, ponencia o proyecto & $\begin{array}{l}\text { Nombre de la revista, de las memorias del congreso o } \\
\text { de proyectos de investigación }\end{array}$ \\
\hline $\begin{array}{l}\text { Estrategia didáctica con el enfoque ciencia, tecnología, } \\
\text { sociedad y ambiente, para la enseñanza de aspectos de } \\
\text { bioquímica. }\end{array}$ & Revista Tecné, Episteme y Didaxis. № 19. p.44-62, 2006. \\
\hline $\begin{array}{l}\text { Construcción de Conocimiento Escolar en Ciencias } \\
\text { naturales a partir de preguntas de los estudiantes. }\end{array}$ & Nodos y Nudos. ,2, 91, p. 29-38, 2005. \\
\hline $\begin{array}{l}\text { Actitudes favorables hacia la Química a partir del enfoque } \\
\text { Ciencia, Tecnología, Sociedad y Ambiente (CTSA). }\end{array}$ & $\begin{array}{l}\text { I Congreso Iberoamericano de Ciencia, Tecnología, Sociedade } \\
\text { Innovación CTS+I, 2006, México. }\end{array}$ \\
\hline $\begin{array}{l}\text { Contribución de las actividades didácticas orientadas } \\
\text { por el enfoque CTSA, en la alfabetización en química en } \\
\text { estudiantes de secundaria. }\end{array}$ & $\begin{array}{l}\text { IV Congreso lberoamericano de educación científica y tecnológica. } \\
\text { CONCYTEC. Lima, Perú. 7-9 nov., } 2006 .\end{array}$ \\
\hline $\begin{array}{l}\text { Relaciones Ciencia, Tecnología, Sociedad y Ambiente a } \\
\text { partir de casos simulados. }\end{array}$ & $\begin{array}{l}\text { I Congreso lberoamericano de Ciencia, Tecnología, Sociedade } \\
\text { Innovación CTS+l, 2006, México. }\end{array}$ \\
\hline $\begin{array}{l}\text { Construcción de conocimiento escolar en Ciencias } \\
\text { Naturales a partir de preguntas de los estudiantes, en } \\
\text { contexto rural. }\end{array}$ & $\begin{array}{l}\text { Primer Encuentro Latinoamericano de Educación Rural, 2005, } \\
\text { Sutatenza. }\end{array}$ \\
\hline $\begin{array}{l}\text { Estrategia pedagógica y didáctica desde el enfoque } \\
\text { Ciencia, Tecnología, Sociedad y Ambiente a partir de las } \\
\text { fumigaciones con glifosato. }\end{array}$ & $\begin{array}{l}\text { VEncuentro Nacional de Pesquisa em Educação em Ciencias, } \\
\text { 2005, Baurú - São Paulo. }\end{array}$ \\
\hline Profesores en formación en contextos de vulnerabilidad & $\begin{array}{l}\text { VIII Jornadas del maestro investigador: la formación de } \\
\text { formadores en la diversidad de contextos, 2006, Medellín. }\end{array}$ \\
\hline $\begin{array}{l}\text { Perspectivas teóricas de la investigación en enseñanza de } \\
\text { las ciencias naturales de acuerdo con el enfoque Ciencia, } \\
\text { Tecnología, Sociedad y Ambiente (CTSA). }\end{array}$ & $\begin{array}{l}\text { I seminario internacional \& seminario nacional de investigación } \\
\text { en educación y pedagogía. CIUP- UPN. Bogotá. 28-31 de mayo } \\
2007 .\end{array}$ \\
\hline
\end{tabular}


En relación con publicaciones desde la línea Didáctica de los Contenidos curri- culares en Química, el grupo ha publicado lo referenciado en la Tabla 6:

Tabla 6. Trabajos publicados en la línea 2 por el grupo Alternaciencias.

\begin{tabular}{|c|c|}
\hline Título del artículo, ponencia o proyecto & $\begin{array}{l}\text { Nombre de la revista, de las memorias del congreso } \\
\text { o de proyectos de investigación }\end{array}$ \\
\hline $\begin{array}{l}\text { De las investigaciones en preconcepciones sobre mol y } \\
\text { cantidad de sustancia hacia el diseño curricular en Química. }\end{array}$ & $\begin{array}{l}\text { Educación y Pedagogía Universidad de Antioquia XVII. 43. p. } \\
\text { 163-175. } 2005\end{array}$ \\
\hline $\begin{array}{l}\text { Evaluación por competencias y estándares de competencia } \\
\text { en el campo de la enseñanza de las ciencias y la educación } \\
\text { ambiental }\end{array}$ & $\begin{array}{l}\text { Enunciación. Universidad Distrital Francisco José de Caldas. } \\
\text { 10. p. 73-84. } 2005\end{array}$ \\
\hline $\begin{array}{l}\text { Conocimiento didáctico del contenido curricular: una } \\
\text { estrategia sustentada en el diseño de tramas conceptuales. }\end{array}$ & $\begin{array}{l}\text { Proyecto CIUP-UPN- DQU-025-07. Vigencia de } 2 \text { años: } 2007 \\
-2008\end{array}$ \\
\hline $\begin{array}{l}\text { El conocimiento didáctico del contenido curricular y } \\
\text { complejización del conocimiento. }\end{array}$ & $\begin{array}{l}\text { IV Congreso lberoamericano de educación científica y } \\
\text { tecnológica. CONCYTEC. Lima, Perú. 7-9 nov., } 2006 .\end{array}$ \\
\hline $\begin{array}{l}\text { Conocimiento didáctico del contenido curricular en química y } \\
\text { el diseño de tramas conceptuales. }\end{array}$ & $\begin{array}{l}\text { I seminario internacional \& seminario Nacional de investigación } \\
\text { en educación y pedagogía. CIUP- UPN. Bogotá. 28-31 de mayo } \\
\text { 2007. Seleccionada para publicación en el libro de este } \\
\text { evento. }\end{array}$ \\
\hline $\begin{array}{l}\text { Tramas histórico-epistemológicas en la evolución de la teoría } \\
\text { estructural en química orgánica. }\end{array}$ & $\begin{array}{l}\text { Tecné, Episteme y Didaxis, TE } \Delta \text {. Universidad Pedagógica } \\
\text { Nacional. No. 21. Primer semestre de 2007. p. 100-118. }\end{array}$ \\
\hline $\begin{array}{l}\text { El conocimiento didáctico del contenido como programa de } \\
\text { investigación: un contexto para la enseñanza de la Química. }\end{array}$ & $\begin{array}{l}\text { III Congreso internacional sobre formación de profesores de } \\
\text { ciencias. Universidad Pedagógica Nacional. Bogotá. 19-21 } \\
\text { sep. de 2007. Memorias digitales del evento. }\end{array}$ \\
\hline $\begin{array}{l}\text { La investigación sobre el conocimiento didáctico del } \\
\text { contenido curricular, el caso en los profesores de química. }\end{array}$ & $\begin{array}{l}\text { III Congreso internacional sobre formación de profesores de } \\
\text { ciencias. Universidad Pedagógica Nacional. Bogotá. 19-21 } \\
\text { sep. de 2007. Memorias digitales del evento }\end{array}$ \\
\hline
\end{tabular}

Por último, el grupo Alternaciencias dirige trabajos de grado y tesis de maestría en docencia de la química desde las dos líneas de investigación. Es un programa académico que tiene, entre otros, retos relacionados con la consolidación del grupo como un referente reconocido a partir de las investigaciones y publicaciones realizadas, con la construcción y desenvolvimiento de nuevos programas de formación inicial y continua de profesores de ciencias (Química), con la elaboración de propuestas curriculares centrados en los marcos teóricos que se vayan consolidando, y con el asesoramiento de instituciones locales y nacionales en cuanto a la enseñanza de la Química.

\section{Grupo Estilos pedagógicos}

El grupo se propone establecer las implicaciones de la visibilización, reflexióncrítica y toma de conciencia de los estilos pedagógicos desde los cuales cada profesor desarrolla su práctica pedagógica, en el desarrollo profesional docente de los profesores de la UPN mediante la Investigación acción. El líder actual de este grupo es el doctor Luis Enrique Salcedo Torres (CIUP, 2007). Este grupo fue clasificado por Colciencias, en octubre de 2006, en categoría B.

La Línea de investigación del grupo es el de la Docencia Universitaria. La docencia universitaria, sus dinámicas, relaciones e interacciones, trasciende de manera contemporánea la mirada instru- 
mental en y la disposición y apropiación de las correspondientes técnicas para enseñar algunos saberes específicos. Ser profesional de la docencia universitaria requiere una comprensión más completa de ésta y sus múltiples circunstancias; uno de los problemas esenciales de las instituciones de Educación Superior consiste en que un número significativo de sus profesores no ha sido formado en el campo de la investigación educativa, menos aún en los campos del saber pedagógico lo cual incide en la calidad académica, así como en la implementación de sus políticas de mejoramiento.

Por lo tanto, la línea de investigación en Docencia Universitaria alberga grupos y proyectos de investigación orientados hacia la disposición de las herramientas teóricas y conceptuales necesarias que permitan fundamentar la formación de los profesores a través de la investigación continua y sistemática en el campo de la educación universitaria (CIUP, 2007).

Algunos de los proyectos destacados del grupo son:
A. Incorporación de las nuevas tecnologías de la información y la comunicación en las prácticas de laboratorio: un complemento al modelo de enseñanza y aprendizaje por investigación (Código COLC-26503-UPN-825-03) donde participan los profesores del Departamento de Química Luis Salcedo, Martha Villarreal y Pedro Nel Zapata.

B. Los estilos pedagógicos y la investigación-acción: implicaciones en el desarrollo profesional docente de los profesores de la Universidad Pedagógica Nacional (Código DPG016-05), proyecto en el que participa el profesor Luis Salcedo.

C. Características de las prácticas Pedagógicas y Didácticas realizadas por los profesores de Química en formación, (código: DQU-024-07). En este proyecto participan los profesores Blanca Cruz, Luis Rincón, Luis Salcedo y Margarita Rendón.

La Tabla 7 presenta algunas de las publicaciones encontradas para el grupo.

Tabla 7. Publicaciones del grupo Estilos pedagógicos.

Título del artículo, ponencia o proyecto

Concepciones y acciones de los profesores de Química sobre la

Concepcion
evaluación.

Docencia por investigación: una opción de trabajo universitario

Actualidades Pedagógicas. Universidad de la Salle. 40. 2001.

La formación de profesores como objeto de investigación curricular y de aula

Actualidades Pedagógicas. Universidad de la Salle. 41. 2002.

Concepciones de los profesores y estudiantes sobre prácticas de I Congreso sobre Formación de Profesores. 2003. En Revista laboratorio del nuevo proyecto curricular de la licenciatura de Tecné, Episteme y Didaxis, TE $\Delta$. Universidad Pedagógica Química de la Universidad Pedagógica Nacional.

Las actividades experimentales en la enseñanza de la Química en el nivel superior.
Nombre de la revista, de las memorias del congreso o de proyectos de investigación

Educación y Pedagogía. Universidad de Antioquia No. 25 p. 177-207. 1999. 


\section{Grupo Ciencia, acciones y creencias}

El grupo Ciencia, acciones y creencias es un grupo interinstitucional, conformado por profesores de la Universidad Pedagógica Nacional y la Universidad del Valle. Dentro de los profesores del Departamento de Química que participan están los doctores Luis Salcedo, Fidel Cárdenas y Pedro Nel Zapata. En la actualidad está clasificado en la Categoría A de Colciencias.

Dentro de las líneas de investigación del grupo están:
- Acciones de maestros de ciencias: creencias, roles, metas y contextos en la enseñanza y el aprendizaje.

- La relación entre el conocimiento común y conocimiento científico escolar.

- Evaluación en ciencias.

- Elaboración de los conceptos científicos.

Las tablas 8 y 9 presentan algunas de las publicaciones en revistas y libros del grupo.

Tabla 8. Algunas de las publicaciones en revistas del grupo Ciencia, acciones y creencias.

\begin{tabular}{|c|c|}
\hline Título del artículo, & Nombre de la revista \\
\hline $\begin{array}{l}\text { Actitudes de los profesores de ciencias experimentales hacia la } \\
\text { investigación en educación }\end{array}$ & Diógenes. 5. 2. p. 195-206. 1998. \\
\hline $\begin{array}{l}\text { Contribución a la formación científica de los profesores de } \\
\text { Química. }\end{array}$ & Actualidades Pedagógicas. 39. 1 1. p. 40-51. 2000. \\
\hline $\begin{array}{l}\text { Algunas apreciaciones de los estudiantes a cerca de los } \\
\text { miniproyectos como apoyo a la enseñanza de la química a nivel } \\
\text { universitario. }\end{array}$ & Revista de investigación. 1 p. 69-79. 2001. \\
\hline Competencias y dificultades de aprendizaje en química. & Boletín de la Sociedad Química del Perú. 67 1. p. 47-60. 2001. \\
\hline Creencias acerca del cambio en la enseñanza de las ciencias. & Enseñanza de las Ciencias. 6 1. 1. p. 369 -370. 2001 \\
\hline $\begin{array}{l}\text { Competencias en Química en los primeros años en la educación } \\
\text { básica en Bogotá. }\end{array}$ & Revista de la Sociedad Química de México 46. 2002. \\
\hline $\begin{array}{l}\text { Concepciones de los profesores y estudiantes sobre prácticas } \\
\text { de laboratorio del nuevo proyecto curricular de la Licenciatura } \\
\text { en Química de la UPN. }\end{array}$ & Tecné, Episteme y Didaxis. TE $\Delta$. 15. 1. 1. p. 1-10. 2004 \\
\hline
\end{tabular}

Tabla 9. Algunos de los libros publicados por integrantes el grupo Ciencia, acciones y creencias.

\begin{tabular}{llcl}
\hline Nombre del libro & Autores & Año & Editorial \\
\hline Acciones y creencias. Tomo I. Tesoro oculto del profesor & Salcedo Torres Luis & 2001 & ARFO LTDA \\
\hline $\begin{array}{l}\text { Acciones y creencias. Tomo Il. Análisis e interpretación de creencias } \\
\text { de docentes de Física. }\end{array}$ & Salcedo Torres Luis & 2001 & ARFO LTDA \\
\hline $\begin{array}{l}\text { Acciones y Creencias. Tomo IV. Análisis e interpretación de } \\
\text { creencias de docentes en Biología y Ciencias Naturales. }\end{array}$ & Salcedo Torres Luis & 2001 & ARFO LTDA \\
\hline $\begin{array}{l}\text { Pedagogía y Didáctica de las Ciencias Experimentales. Hacia una } \\
\text { Enseñanza y un Aprendizaje por Investigación. }\end{array}$ & Salcedo Torres Luis & 2003 & ARFO LTDA \\
\hline
\end{tabular}

Por último, la siguiente tabla (Tabla 10) permite ver un consolidado relacionado con los proyectos vigentes que tienen en la actualidad los grupos de investigación del Departamento, el número de líneas, el número de profesores de planta, catedráticos y ocasionales, vinculados a éstos y su clasificación ante Colciencias. Es de anotar, que en los últimos años, la productividad académica e investigativa en el Departamento se ha ido consolidado más. Allí participan todos los profesores de planta, los estudiantes de pregrado y de postgrado 
quienes con su trabajo de grado o de tesis, según sea el caso, se vinculan a los grupos de investigación.

A manera de consideración final, se considera que es necesario hacer un análisis que muestre la tendencia de cada grupo en cuanto a sus líneas de investigación, con el fin de consolidar marcadas diferencias o tendencias, es decir, analizar cómo la pluralidad en las líneas y grupos de investigación divide, integra o articula, pues se ve más como sumatoria de esfuerzos individuales de cada línea o de cada grupo y no una combinatoria de éstos. Las temáticas de los grupos pueden ser consensuadas por periodos de tiempo, por ejemplo, investigar desde prioridades internacionales (CTS/I-A, problemas enfocados en revistas sobre enseñanza de las ciencias o proyectos internacionales), que tengan un acercamiento al doctorado y a la maestría, desde necesidades nacionales (y no tan locales) a las líneas de investigación internacional.

Tabla 10. Distribución de los grupos de investigación en el Departamento de Química por líneas, profesores y proyectos.

\begin{tabular}{|c|c|c|c|c|c|c|c|c|c|}
\hline Departamento & $\begin{array}{l}\text { Grupo de } \\
\text { investigación }\end{array}$ & Coordinador & $\begin{array}{l}\text { N. }{ }^{\circ} \text { de } \\
\text { líneas }\end{array}$ & $\begin{array}{c}\text { N.º de } \\
\text { Profesores } \\
\text { de cátedra }\end{array}$ & $\begin{array}{c}\text { N. }{ }^{\circ} \text { de } \\
\text { profesores } \\
\text { de planta }\end{array}$ & $\begin{array}{c}\mathrm{N} .^{\circ} \text { de } \\
\text { profesores } \\
\text { Ocasionales }\end{array}$ & $\begin{array}{c}\mathrm{N} .^{\circ} \mathrm{de} \\
\text { proyectos }\end{array}$ & $\begin{array}{c}\text { Clasificación } \\
\text { Colciencias }\end{array}$ & $\begin{array}{c}\text { Horas de } \\
\text { trabajo } \\
\text { semanal } \\
\text { por grupo }\end{array}$ \\
\hline \multirow{5}{*}{ Química } & $\begin{array}{l}\text { Representaciones } \\
\text { y conceptos } \\
\text { científicos }\end{array}$ & $\begin{array}{l}\text { Rómulo } \\
\text { Gallego } \\
\text { Badillo }\end{array}$ & 2 & 1 & 2 & 0 & 1 & $A$ & 10 \\
\hline & $\begin{array}{l}\text { Desarrollo de } \\
\text { habilidades de } \\
\text { pensamiento y } \\
\text { enseñanza de las } \\
\text { ciencias }\end{array}$ & $\begin{array}{l}\text { Pedro Nel } \\
\text { Zapata }\end{array}$ & 1 & 3 & 1 & 0 & 0 & $\begin{array}{c}\text { no se } \\
\text { clasifica }\end{array}$ & 10 \\
\hline & $\begin{array}{l}\text { La didáctica y sus } \\
\text { ciencias }\end{array}$ & $\begin{array}{l}\text { Yolanda } \\
\text { Ladino } \\
\text { Ospina }\end{array}$ & 5 & 3 & 4 & 0 & 2 & C & 10 \\
\hline & $\begin{array}{l}\text { Estilos } \\
\text { pedagógicos }\end{array}$ & $\begin{array}{l}\text { Luis E. } \\
\text { Salcedo, }\end{array}$ & 1 & 0 & 3 & 0 & 1 & $B$ & 10 \\
\hline & $\begin{array}{l}\text { Ciencias, } \\
\text { Acciones } \\
\text { y creencias } \\
\text { (Grupo } \\
\text { interinstitucional) }\end{array}$ & $\begin{array}{l}\text { Luis Salcedo, } \\
\text { Pedro Nel } \\
\text { Zapata, F. } \\
\text { Cárdenas }\end{array}$ & 3 & 1 & 2 & 0 & 1 & $A$ & 10 \\
\hline
\end{tabular}

En necesario investigar nuestros propios programas: el Proyecto Curricular Experimental de Licenciatura en Química y la Maestría en Docencia de la Química, para que cualquier reforma por más adjetiva o sustantiva que sea, tenga un sustento que valide los cambios reali- zados. Las siguientes son pregunta que los Grupos de investigación debemos plantearnos en cuanto a los programas que ofrecemos como Departamento: la opinión de los estudiantes y egresados frente a la satisfacción e insatisfacción del programa, ¿Qué tipos de tesis o de 
trabajos de grado se han desarrollado, son pertinentes para el profesional que se forma y dada la naturaleza de los programas? ¿Cuál es su articulación con las líneas de investigación? ¿Cuáles son las necesidades en Educación química en Colombia y en el exterior? ¿Existe una planeación estratégica frente a debilidades, oportunidades, fortalezas y amenazas, es decir un DOFA? ¿Cuál es la pertinencia de los postulados constructivistas? ¿Qué artículos se producen desde la Maestría (o cuáles son las as- piraciones de nuestros egresados en su carrera profesional) y desde los trabajos de pregrado? ¿Se ha dado solución a los problemas en educación química en los colegios de Bogotá y del país? ¿Nuestros programas de pregrado y postgrado satisfacen las necesidades educativas? Concluir sobre estas preguntas significa hacer investigación de nuestros programas de formación inicial y avanzada, retos en los cuales nuestros grupos ya han empezado a trabajar.

\section{La investigación del último decenio en tecnologías de la información del Departamento de Tecnología}

Desde 1996 el Departamento de Tecnología ha venido trabajando en el área de las tecnologías de la información y la comunicación para la generación de modelos teóricos y metodológicos que incluyen el diseño, producción, validación e investigación a partir de la psicología cognitiva, la ciencia cognitiva y su relación con la inteligencia artificial. La investigación realizada en el Departamento, ha venido fomentando y fortaleciendo la visión teórica, epistemológica, metodológica, tecnológica y pedagógica de los programas de pregrado y posgrado. La creación de grupos de investigación comprometidos con el desarrollo de estos programas, ha dado apertura a la consolidación de líneas de

\footnotetext{
* Profesor e Investigador grupo TECNICE - UPN y Director Departamento de Tecnología de la Universidad Pedagógica Nacional.
}

Luis Bayardo Sanabria R.

investigación en temas tales como: el aprendizaje autónomo, el aprendizaje por descubrimiento, la formación de competencias docentes con el uso de ambientes hipermediales, la comprensión de la representación del espacio en invidentes con el uso de ayudas aumentativas, el aprendizaje colaborativo y la intervención de agentes artificiales para la comprensión de conceptos en escenarios hipertextuales. A partir de estos campos, la investigación en los últimos diez años ha girado en torno a los siguientes aspectos:

- Incorporación de las tecnologías de la información al desarrollo de un modelo de pedagogía computacional

- Desarrollo de ambientes de aprendizaje que incluyen el diseño de dispositivos y ambientes hipermediales que sirven como ayuda aumentativa para estudiar la representación espacial en 
discapacitados visuales y el aprendizaje en personas sordomudas.

- Desarrollo de software como instrumento para investigar los procesos de aprendizaje de los individuos.

- Desarrollo de software como instrumento para investigar el desarrollo de habilidades cognitivas y metacognitivas.

\section{Enfoque de la investigación en informática educativa}

La investigación en tecnologías de la información aplicadas a la educación plantea un enfoque relacionado con el estudio del comportamiento del ser humano y el conocimiento del mundo. El estudio del comportamiento, se explica con la incorporación de modelos computacionales para investigar procesos de aprendizaje. El conocimiento del mundo se evidencia en la representación como resultado del modelamiento de su ontología. A partir de esta concepción surgen posiciones epistemológicas como las relacionadas en la publicación Hilos conductores del aprendizaje autónomo y los procesos de razonamiento elaborado por Maldonado y otros en 20032. Este articulo señala cinco posiciones:

- Representar es comprender

- La estadística apoya la generalización mediante la normalización.

- Las lógicas cualitativa y cuantitativa son dimensiones complementarias en una misma representación del mundo.

- El mundo existe a través de ontologías.

2 Revista TE $\Delta$. Tecné, Episteme, Didaxis. 13, 58-73, 2003.
La investigación experimental es fuente de metáforas para orientar la acción en los entornos naturales.

\section{Participación de los grupos de investigación}

La participación de los grupos de investigación del Departamento ha permitido representar a la Universidad Pedagógica Nacional en eventos nacionales e internacionales como los Congresos Iberoamericanos de informática educativa, los diferentes Talleres Internacionales de Software Educativo. Con estas iniciativas se ha venido fortaleciendo la comunidad educativa que hace parte de nuestros programas académicos. Los grupos investigación del departamento se han establecido de acuerdo a la experiencia en investigaciones y a las necesidades de los proyectos curriculares.

La vinculación con grupos de otras universidades como la Universidad Pedagógica y Tecnológica de Colombia, la Universidad Distrital Francisco José de Caldas, ha generado escenarios de diálogo e intercambio de experiencias, dando impulso al desarrollo investigativo de programas y proyectos de formación docente en el departamento.

Uno de los grupos con mayor trayectoria, no solamente en el departamento sino en la universidad es TECNICE, escalafonado en Categoría A en Colciencias, cuyos integrantes han producido la mayor parte de investigación con el uso de las tecnologías de la información. La participación de este grupo como miembro activo de la Red Iberoamericana de Informática Educativa-Capítulo Colombia, ha permitido fortalecer los vínculos con otras instituciones que trabajan en esta línea, donde se han podido com- 
partir experiencias en beneficio de la investigación del departamento. De la misma forma, el grupo se ha asociado con otros grupos de la Universidad como HIMINI del departamento de Lenguas, escalafonado también en Colciencias, donde participan algunos miembros de nuestro departamento con el objeto de desarrollar propuestas con intereses comunes para beneficio de los dos departamentos.

A partir de la incorporación de la investigación al desarrollo del programa de Posgrado en Tecnologías de la Información, se han venido creando nuevos grupos, los cuales poseen su registro en Colciencias. Sus trabajos se relacionan con ayudas para discapacitados, aprendizaje en e-Learning y procesos de aprendizaje en tecnología. El grupo TECNICE con su experiencia y aportes ha venido fomentando la creación de estos grupos. Los grupos nacientes trabajan en función de aportar su desarrollo investigativo a los programas del departamento. Podemos mencionar a: Synapsis, Kenta y Episteme como los nuevos grupos del departamento.

\section{Generación de trabajos de investigación}

El trabajo de investigación generado en las diferentes líneas de investigación se visualiza con la participación en la elaboración de los siguientes proyectos:

\begin{tabular}{ll}
\hline Año & Título del proyecto \\
\hline $1997-1999$ & $\begin{array}{l}\text { Razonamiento espacial para el desarrollo de la capacidad de diseño apoyado por computador. (Financiado por } \\
\text { UPN y Colciencias). }\end{array}$ \\
\hline $1998-2000$ & $\begin{array}{l}\text { Razonamiento espacial y aprendizaje significativo: influencia de la riqueza de conexiones entre conceptos. } \\
\text { (Financiado por UPN e IDEP). }\end{array}$ \\
\hline $1999-2000$ & $\begin{array}{l}\text { Diseño de un ambiente de aprendizaje para el desarrollo de la cognición y la metacognición. (Financiado por } \\
\text { UPN e IDEP). }\end{array}$ \\
\hline $1999-2001$ & $\begin{array}{l}\text { Ambiente para el aprendizaje significativo: un ambiente para el diseño de hipertextos y evaluación del } \\
\text { aprendizaje en ciencias sociales. (Financiado por UPN y Colciencias). }\end{array}$ \\
\hline $2001-2002$ & $\begin{array}{l}\text { Agentes Inteligentes de Software orientados al juego de roles para el aprendizaje significativo de la } \\
\text { Constitución Colombiana. (Financiado por UPN y Colciencias). }\end{array}$ \\
\hline $2003-2005$ & $\begin{array}{l}\text { Incidencia de la variedad de niveles de complejidad sobre el aprendizaje en la solución de problemas. } \\
\text { (Financiado por UPN a través del CIUP). }\end{array}$ \\
\hline $2004-2006$ & $\begin{array}{l}\text { Diseño y desarrollo de un prototipo basado en visión artificial y lógica difusa para identificar procesos de } \\
\text { representación espacial en discapacitados visuales que utilizan este dispositivo como ayuda aumentativa. } \\
\text { (Financiado por UPN y Colciencias). }\end{array}$ \\
\hline $2004-2006$ & \begin{tabular}{l} 
Programas de computador para el desarrollo de competencias docentes. (Financiado por UPN y Colciencias). \\
\hline $2005-2007$
\end{tabular} $\begin{array}{l}\text { Procesos cognitivos y metacognitivos en la solución de problemas de movimiento de figuras en el plano. } \\
\text { (Financiado por UPN a través del CIUP). }\end{array}$ \\
\hline $2003-2004$ & $\begin{array}{l}\text { La autorregulación como mecanismo de evaluación en el área de tecnología e informática. (Financiado por } \\
\text { UPN e IDEP). }\end{array}$ \\
\hline $\begin{array}{l}\text { Agentes de Software generadores de preguntas y el desarrollo de la competencia cognitiva de hacer } \\
\text { inferencias: la comprensión y la inferencia en diferentes niveles de profundidad en ambientes hipermediales. } \\
\text { (Financiado por UPN y Colciencias). }\end{array}$ \\
\hline
\end{tabular}

Con relación al desarrollo de trabajos originados desde la concepción en Tecnología, se pueden mencionar algunas investigaciones que se han desarrollado como aporte a la formación del licenciado del Departamento. 


\begin{tabular}{ll}
\hline Año & Título del proyecto \\
\hline 2004 & $\begin{array}{l}\text { Sistematización y evaluación de una experiencia de formación en el área de circuitos. (Financiado por la } \\
\text { UPN a través del CIUP). }\end{array}$ \\
\hline 2004 & Razonamiento espacial en cinemática de mecanismos. (Financiado por la UPN a través del CIUP). \\
\hline 2004 & $\begin{array}{l}\text { Incidencia de los sistemas representacionales de conocimiento diagramático y matemático en la solución } \\
\text { de problemas tecnológicos. (Financiado por la UPN a través del CIUP). }\end{array}$ \\
\hline 2004 & $\begin{array}{l}\text { Modelo de selección, uso y diseño de actividades pedagógicas a partir de los objetos tecnológicos como } \\
\text { mediadores del aprendizaje en el área de tecnología e informática. (Financiado por la UPN a través del } \\
\text { CIUP). }\end{array}$ \\
\hline 2006 & $\begin{array}{l}\text { Propuesta de un nuevo sistema de admisión para los programas de la Facultad de Ciencia y Tecnología. } \\
\text { (Financiado por la UPN a través del CIUP). }\end{array}$ \\
\hline $\begin{array}{l}\text { Análisis de la cultura de tecnologías de la información y la comunicación en la UPN. (Financiado por la UPN } \\
\text { a través del CIUP). }\end{array}$ \\
\hline $\begin{array}{l}\text { Aprendizaje de actividades motoras en procesos prensiles con el uso de una Prótesis Mecatrónica } \\
\text { controlada por señales mioeléctricas y de voz, en personas amputadas entre codo y muñeca. (Financiado } \\
\text { por la UPN a través del CIUP). }\end{array}$ \\
\hline $\begin{array}{l}\text { Impacto de las funciones cognitivas de entrada en la solución de problemas tecnológicos. (Financiado por } \\
\text { la UPN a través del CIUP). }\end{array}$
\end{tabular}

\section{Producción intelectual}

La producción intelectual se presenta con los siguientes productos:

\section{Libros publicados}

- Formación de competencias docentes. 1 ed. Bogotá: Imprenta Nacional, 2006, v.1. p.140. Autores: Sanabria, L. \& Macias. D.

- La representación espacial en invidentes congénitos con apoyo de un dispositivo mecatrónico. 1 ed. Bogotá: Imprenta Nacional, 2006, v.1. p.224. Autores: López, O.; Sanabria, L.; Sarmiento, L.; Ibáñez, J. \& Valencia, N.

- La complejidad en la solución de problemas, 1 ed. Bogotá: Universidad Pedagógica Nacional, 2005, v.1. p.140. Autores: López, O.; Maldonado, L.; Sanabria, L. \& Ibáñez, J.

- Aprendizaje autorregulado de la tecnología. 1 ed. Bogotá: Universidad Pedagógica Nacional, 2004, v.150. p.337. Autores: López, O.; Maldonado, L.; Sanabria, L.; Ibáñez, J.; Sarmiento, L.; Quintero, V. \& Valencia, N.

- Ontología y aprendizaje de la Geografía: software para representar y software para comprender. 1 ed. Bogotá: Grupo TECNICE - Universidad Pedagógica Nacional, 2002, v.1. p.183. Autores: Maldonado, L.; Sanabria, L. \& Ortega, N.

- Metacognición y razonamiento espacial en juegos de computador, 1 ed. Bogotá: Universidad Pedagógica Nacional, 1999, v.1. p.237. Autores: Maldonado, L.; Sanabria, L.; Macias, D.; Ibáñez, J.; Fonseca, O.; Ortega, N. \& Rubio, M.

- Ambiente computarizado para el aprendizaje autodirigido del diseñoACA2. Cooperativa Editorial Magisterio, Bogotá D.C. p.109 Vol. 1, 2001. Autores: Maldonado, L.

- Razonamiento espacial y aprendizaje significativo. Cooperativa Editorial Magisterio, Bogotá D.C. p.379 Vol. 1. 2001. Autores: Maldonado, L.; Macias, D.; Ibáñez, J.; Ortega, N. \& Rubio, M.

- Relación simuladores y aprendizaje en problemas de descubrimiento. Autores: Maldonado, L.; Macias, D.; Ibáñez, J.; Ortega, N. \& Sarmiento, L. Cooperativa Editorial UPN, Bogotá D.C. p.160, Vol. 1. 2001. 


\section{Capítulos de libros}

- Niveles de complejidad en la solución de problemas. LOM Ediciones S.A. V. 1, p. 79 - 85, 2006, Chile. López, O.; Sanabria, L. \& Quintero, V.

- Desarrollo de la cognición espacial en invidentes congénitos con apoyo de dispositivos tecnológicos. LOM Ediciones S.A. V. 1, p. 79 - 85, 2006, Chile. López, O.; Sanabria, L. \& Ibáñez, J.

- Programas de computador para el desarrollo de competencias docentes. LOM Ediciones S.A. V. 1, p. 79 - 85, 2006, Chile. Autor: Sanabria, L.

- Question generator software agents versus shells for building hipertext In: Computers and Education.1 ed. Dordrecht, The Netherlands : Kluwer Academic Publishers, 2003. Autores: Maldonado, L.; Sanabria, L.; Macias, D. \& Ortega, N.

- Microsistemas Motivacionales y Asimilación de Estrategias en Problemas de Descubrimiento En: La Formación de Educadores en Colombia. 1 ed. Bogotá: ARFO Editores e Impresores Ltda., 2001. Autores: Sanabria, L.; Ibáñez, J.; Macias, D.

- Artículos publicados en revistas indexadas

- Aprendizaje autorregulado con proyectos de aula en el área de tecnología informática realizado realizado en el colegio distrital Rodrígo Lara Bonilla de Bogotá, D.C., Colombia. Revista de Investigación. Universidad de la Salle Bogotá: v.5, n.1, p.85 - 98, 2005. Autores: López, O.; Maldonado, L.; Sanabria, L.; Ibáñez, J.; Sarmiento, L.; Quintero, V. \& Valencia, N.

- Agente de Software Q y el Aprendizaje de Modelos Conceptuales. T $\Sigma \Delta$. Tecné, Episteme y Didaxis, Universidad Pedagógica Nacional. Arfo Edi- tores, v.14, p.14 - 40, 2003. Autores: Maldonado, L.; Sanabria, L.; Ibáñez, J.; Macias, D. \& Ortega, N.

- Hilos conductores del aprendizaje autónomo y los procesos de razo-

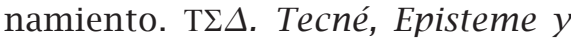
Didaxis, Universidad Pedagógica Nacional. v.13, p.58 - 73, 2003. Maldonado, L.; Sanabria, L.; Macias, D. \& Ortega, N.

- Incidencia de la eficacia y la eficiencia de la solución de problemas de movimiento de figuras geométricas en ambientes computacionales. Revista de Investigación. Universidad de la Salle Bogotá: , v.7, No.1, 2007. López, O.; Sanabria, L. \& Ibáñez, J.

- Incidencia de un modelo de experto y de un simulador en las decisiones sobre materiales para el diseño de máquinas. T $\Sigma \Delta$, Tecné, Episteme y Didaxis, Universidad Pedagógica Nacional No. 18, 2005. Autores: Maldonado, L. \& López, O.

\section{Software elaborado para investigación}

- Complex Motion Multimedia, 2004.

- $\quad$ Agente Q Multimedia, 2002.

- Agentes de software que juegan roles Multimedia, 2002.

- Hipertexto Estructura de Poder Multimedia, 2002.

- Juegos para Argumentar Computacional, 2002.

- Hipertextos de Geografía de Colombia Multimedia, 2001.

- Hipertexto Arte Geométrico Multimedia.

- Hipertexto la Grúa a través de la Historia Multimedia, 2000.

- Hipertexto Mi Máquina Multimedia, 2000.

- Agente Preguntón Computacional, 1999. 
- SIMAS Computacional, 1999.

- Juego Líneas al Azar Computacional, 1997.

- Juego Líneas en equilibrio Computacional, 1997.

- Juego Posición y Dirección Computacional, 1997.

- Juego Puntos en Equilibrio Computacional, 1997.

- Juego Razonamiento sobre Mecanismos Computacional, 1997.

- Juego Rompecabezas de Piezas Ensamblables Computacional, 1997.

- Juego Rompecabezas VEGA VEGA JG Computacional, 1997.

- Laboratorio del Color Computacional.

\section{Participación en eventos nacionales e} internacionales

La participación del departamento a nivel nacional e internacional se muestra con el trabajo presentado a través de ponencias:

- Desarrollo de la cognición espacial en invidentes congénitos con apoyo de dispositivos tecnológicos. I Seminario Internacional y VI Nacional de Investigaciones en Educación y Pedagogía, Bogotá, 2007.

- Incidencia en la eficacia y la eficiencia de la solución de problemas de movimiento de figuras geométricas en ambientes computacionales. I Seminario Internacional y VI Nacional de Investigaciones en Educación y Pedagogía, Bogotá, 2007.

- Niveles de complejidad en la solución de problemas. $\mathrm{X}$ Taller Internacional de Software, Santiago de Chile, 2006.

- Desarrollo de la cognición espacial en invidentes congénitos con apoyo de dispositivos tecnológicos. $\mathrm{X}$ Taller
Internacional de Software, Santiago de Chile, 2006.

- Programas de computador para el desarrollo de competencias docentes. $\mathrm{X}$ Taller Internacional de Software, Santiago de Chile, 2006.

- Desarrollo de la cognición espacial en invidentes congénitos con apoyo de dispositivos tecnológicos. VIII Congreso Colombiano de Informática Educativa, Cali, 2006.

- Ambiente de aprendizaje basado en un agente de software orientado al juego de roles. VII congreso iberoamericano de informática educativa, Monterrey - México, 2004.

- Agente Q para estructuración de sistemas conceptuales: validación en entornos hipertextuales y textuales. VIII Taller Internacional de Software Educativo, Santiago de Chile, 2003.

- Agentes inteligentes de software orientados al juego de roles para el aprendizaje significativo de la constitución colombiana "TUTELON". VIII Taller Internacional de Software Educativo, Santiago de Chile, 2003.

- Agentes de software generadores de preguntas versus programas para construir hipertextos: efecto en la comprensión de estructuras conceptuales. Memorias VI Congreso Iberoamericano de Informática Educativa y IV simposio internacional de informática educativa y VII taller internacional de software educativo, Vigo, España, 2002.

- Hilos conductores del aprendizaje autónomo y los procesos de razonamiento. IV Foro Colombiano de Investigadores en Informática Educativa, Cartagena, 2002. 
Proyección de la investigación en el departamento

Los propósitos de la investigación del Departamento de Tecnología, se focalizan en los siguientes aspectos:

- Integración de la investigación a los desarrollos curriculares de los programas del departamento.

- Producción y aplicación de conocimiento en las áreas a partir de los proyectos generados en los grupos de investigación.

- Fomento de la investigación desde la práctica pedagógica, los semilleros de investigación y los proyectos de grado.
- Utilización de ambientes de aprendizaje real y virtual para estudiar el desarrollo de habilidades cognitivas y los procesos de aprendizaje.

Para el próximo decenio se prevé la aplicación de la investigación a la reformulación de propuestas en formación de docentes y cualificación de los grupos nacientes en el campo de la educación en Tecnología. Los resultados y avances en el conocimiento generados a partir del proceso investigativo, será una fuente que alimente las estructuras curriculares de los programas orientados en el Departamento. $\boldsymbol{\Delta}$ 